\title{
Single grain noble gas analysis of Antarctic micrometeorites by stepwise heating method with a newly constructed miniature furnace
}

\author{
Ken-ichi Bajo ${ }^{1 *}$, Tomohiro Akaida ${ }^{1}$, Noriaki Ohashi ${ }^{\dagger \dagger}$, Takaaki Noguchi ${ }^{2}$, Tomoki Nakamura ${ }^{3}$, \\ Yoshinobu Nakamura ${ }^{1}$, Hirochika Sumino ${ }^{1}$, and Keisuke Nagao ${ }^{1}$ \\ ${ }^{1}$ Geochemical Research Center, Graduate School of Science, University of Tokyo, \\ Hongo 7-3-1, Bunkyo-ku, Tokyo 113-0033, Japan \\ ${ }^{2}$ College of Science, Ibaraki University, 2-1-1 Bunkyo, Mito 310-8512, Japan \\ ${ }^{3}$ Department of Earth Science, Graduate School of Science, Tohoku University, \\ 6-3 Aramaki Aza-Aoba, Aoba-ku, Sendai 980-8578, Japan
}

(Received September 27, 2010; Revised July 31, 2011; Accepted August 2, 2011; Online published February 2, 2012)

\begin{abstract}
Ten micrometeorites weighing 0.14-18.5 $\mu \mathrm{g}$, each retrieved from surface snow near the Dome Fuji Station, Antarctica (snow-AMMs), were studied to elucidate their noble gases, mineralogy, morphology, and chemical compositions. Low densities in the range of $0.2-1.4 \mathrm{~g} / \mathrm{cm}^{3}$ estimated for seven samples suggested a porous inner structure. Noble gases were extracted from each particle using stepwise heating with a laboratory manufactured miniature furnace. Isotopic ratios of $\mathrm{He}$ and $\mathrm{Ne}$ indicate that the light noble gases with high ${ }^{4} \mathrm{He}$ concentrations ranging from $10^{-2}$ to $10^{-4} \mathrm{~cm}^{3} \mathrm{STP} / \mathrm{g}$ are mostly of solar origin. The higher concentrations of ${ }^{4} \mathrm{He}$ observed for several samples are comparable with those of IDPs enriched in solar He, but exceed those reported for ice-AMMs. In contrast to $\mathrm{He}$ and $\mathrm{Ne}$, heavy noble gases $\mathrm{Ar}, \mathrm{Kr}$, and $\mathrm{Xe}$ are primordial ones resembling Q-gas trapped in chondrites, although a small contribution of solar $\mathrm{Ar}$ is indicated for some samples with higher ${ }^{36} \mathrm{Ar} /{ }^{132} \mathrm{Xe}$ ratios than that for the Q-gas. Three particles released appreciable amounts of He at temperatures lower than $800^{\circ} \mathrm{C}$, suggesting heating temperatures lower than $700^{\circ} \mathrm{C}$ at the time of atmospheric entry. Other particles released at most $10 \%$ of total He at the temperatures up to $800^{\circ} \mathrm{C}$. Based on their sizes, weights, and release profiles of ${ }^{4} \mathrm{He}$, initial speeds of less than $14 \mathrm{~km} / \mathrm{s}$ at atmospheric entry were indicated for the particles. The slow entry speeds imply that all the snow-AMMs studied in this work were likely derived from asteroids. The present work demonstrates that the miniature furnace can be applicable to noble gas analysis of tiny grains from the Itokawa asteroidal regolith materials returned by the Hayabusa mission.
\end{abstract}

Key words: Noble gases, snow Antarctic micrometeorites, miniature furnace, stepwise heating, entry velocity.

\section{Introduction}

Extraterrestrial materials smaller than $2 \mathrm{~mm}$ in diameter collected mainly in the stratosphere and the polar regions are designated as interplanetary dust particles (IDPs) and micrometeorites (MMs) (Brownlee, 1985; Rubin and Grossman, 2010). Large-scale collection programs have been conducted in polar regions such as Greenland and Antarctica since 1986, yielding numerous MMs (e.g. Maurette et al., 1986, 1987, 1991; Koeberl and Hagen, 1989; Cresswell and Herd, 1992; Taylor et al., 1998; Nakamura et al., 1999; Yada and Kojima, 2000; Iwata and Imae, 2001). Among the MMs, those collected in Antarctica are now designated as Antarctic micrometeorites (AMMs). Although we are recommend calling AMMs retrieved from blue ice fields "blue-ice-field AMMs" as sug-

\footnotetext{
*Present address: Department of Natural History Sciences, Hokkaido University, N10W8, Kita-ku, Sapporo 060-0810, Japan.

${ }^{\dagger}$ Present address: NEC Networks and System Integration Corporation, 1-39-9 Higashi-shinagawa, Tokyo 140-8620, Japan.

Copyright (C) The Society of Geomagnetism and Earth, Planetary and Space Sciences (SGEPSS); The Seismological Society of Japan; The Volcanological Society of Japan; The Geodetic Society of Japan; The Japanese Society for Planetary Sciences; TERRAPUB.
}

doi: $10.5047 /$ eps.2011.08.001 gested by Duprat et al. (2007), here we will call them "iceAMMs" for simplicity. Additionally, we will call AMMs retrieved from snow "snow-AMMs" to distinguish them from "ice-AMMs". The snow-AMMs fell recently, and thus are affected much less by weathering and aqueous alteration effects compared to the ice-AMMs.

Although it is likely that MMs derive from asteroids and comets as do IDPs, those obviously originating from very primitive parent bodies formed in the cold region of the outer solar system have not been identified. Recently, ultracarbonaceous snow-AMMs from near Concordia Station that have a large $\mathrm{D} / \mathrm{H}$ anomaly in the carbonaceous material have been identified (Duprat et al., 2010). This isotopic anomaly suggests that these ultracarbonaceous MMs may be from the outer reaches of the solar system, a source not sampled until recently (Duprat et al., 2010). Their results suggest that snow-AMMs contain MMs that may be derived from both asteroids and comets. In 2006 we initiated a study of snow-AMMs collected from surface snow near the Dome Fuji Station (Noguchi et al., 2006).

Single-particle noble gas analyses have been reported at several laboratories, as reviewed in Nagao (1998). Rajan et al. (1977) measured very high concentrations of ${ }^{4} \mathrm{He}$ (up to $0.25 \mathrm{~cm}^{3} \mathrm{STP} / \mathrm{g}$ ) in 10 IDPs weighing an estimated $0.2-24$ 
ng and concluded that the He was implanted into the particles in space from the solar wind. Hudson et al. (1981) measured all noble gases except for He in 13 IDPs (ca. $10 \mathrm{ng}$ total weight) by heating them. Light noble gas compositions of the IDPs resembled those of solar-gas-rich meteorites, but heavy noble gases resembled planetary ones enriched in carbonaceous chondritic material. Nier and Schlutter (1990) and Nier et al. (1990) reported He and Ne isotopic ratios attributed to implantation of solar energetic particles ("SEP") in individual IDPs and spherules from deep sea sediments, although this composition has now been shown to be implantation of mass discriminated solar wind "SW" (Grimberg et al., 2008).

Laser heating methods have been used to extract noble gases from single IDPs; the measured $\mathrm{He}, \mathrm{Ne}$, and Ar were of solar origin (Kehm et al., 1998, 2002). Isotopic compositions of all noble gases for more than 100 individual iceAMMs have been measured using a Nd-YAG laser combined with a low blank and highly sensitive mass spectrometer (e.g. Osawa and Nagao, 2002; Osawa et al., 2000, $2003 \mathrm{a}, \mathrm{b}, 2010)$. Concentrations and isotopic ratios of noble gases in the ice-AMMs reported by them clearly indicated that they were irradiated by solar particles in space, although the duration of the solar gas irradiation might be less than 1 Myr for most AMMs, as suggested by the low concentration of cosmic-ray-produced ${ }^{21} \mathrm{Ne}$.

The extent of heating of MMs and IDPs during deceleration in the atmosphere depends mainly on their entry velocities. As suggested from studies of IDPs (e.g. Love and Brownlee, 1991; Nier and Schlutter, 1992, 1993), the entry velocity of each particle is probably related to its parent body, although an overlap exists between the entry velocities of asteroidal and cometary particles (Joswiak et al., 2007). Combined mineralogical and noble gas studies of IDPs show that dust generated from comets with perihelia $<1$ AU can be expected to have entry velocities greater than $18 \mathrm{~km} / \mathrm{s}$, although dust from asteroids with low eccentricities and low inclinations typically have entry velocities of $14 \mathrm{~km} / \mathrm{s}$ at most (Joswiak et al., 2007). Consequently, concentrations and release profiles of implanted solar noble gases might be an indicator for the atmospheric entry heating temperature, which fundamentally depends on the particle's orbit after ejection from a parent body. Snow-AMMs contain particles which might be derived from the outer region of the Solar System (Duprat et al., 2010); therefore, combined studies of noble gases and mineralogy of snowAMMs may yield important information related to their parent bodies.

In this study, the morphology, mineralogy and chemical composition of 10 snow-AMMs were investigated; then noble gases were measured by stepwise heating each particle using a new miniature furnace produced in our laboratory. Combining mineralogical data with heating temperatures experienced by each snow-AMM during passage through the atmosphere allows us to speculate on the origins of these MMs. An additional aim of this experiment is to set up an experimental apparatus and establish analytical techniques that will be available for noble gas analyses of small grains $(<100 \mu \mathrm{m})$ of the Itokawa asteroidal samples returned in 2010 by the Hayabusa sample return mission.

\section{Sample Description and Experimental Meth- ods}

\subsection{Sample descriptions}

The 10 snow-AMMs were retrieved from surface snow near the Dome Fuji Station, Antarctica; they were collected by the 2004 and 2006 Japan Antarctic research expedition teams. The snow samples were transferred from Antarctica via the National Institute of Polar Research in Tokyo to Ibaraki University in a frozen state. The snow was melted and water was filtered to collect fine-grained particles in a class 1000 clean room. The protocol to find snow-AMMs is described in Sakamoto et al. (2010).

Figure 1 shows secondary electron images of the snowAMMs investigated in this study. Table 1 presents sizes of major and minor axes, weights, and major mineral assemblages. Major mineral assemblages were determined using synchrotron radiation X-ray diffraction (SR-XRD) analysis at beam line $3 \mathrm{~A}$ of the Photon Factory Institute of Material Science, High Energy Accelerator Research Organization. Details of SR-XRD are described in Nakamura et al. (2008). Qualitative chemical compositions of the surface of these AMMs were obtained using SEM-EDX without carbon coating.

All the snow-AMMs except for D03IB19 (hereinafter \#19) contain abundant olivine, pyrrhotite, and magnetite. Five of them also contain pyroxene (Table 1). Only D05IB74 (\#74) contains saponite, which suggests that the maximum heating temperature experienced by the \#74 particle did not exceed ca. $600^{\circ} \mathrm{C}$ (Nozaki et al., 2006). This is the only phyllosilicate-rich snow-AMM containing relict olivine found in this study. Another snow-AMM that was probably phyllosilicate-rich before entering the Earth's atmosphere is D03IB18 (\#18). It contains two Fe-rich oxides: magnetite and $\mathrm{Mg}$-bearing wüstite $(\mathrm{Fe}, \mathrm{Mg})_{1-x} \mathrm{O}$. Based on heating experiments (Nozaki et al., 2006), coexistence of these two Fe oxides is common among moderately heated Tagish Lake samples (heated above ca. $700^{\circ} \mathrm{C}$ ), in which Mg-bearing wüstite is a decomposition product of Mg-bearing siderite. Therefore, the \#18 sample probably contained Mg-bearing siderite before atmospheric heating, which exists widely among saponite-rich MMs and meteorites (Brearley and Jones, 1998; Noguchi et al., 2002).

Although morphologies of the snow-AMMs are quite variable (Fig. 1), their main mineral assemblages are not, as described above. These mineral assemblages can be accomplished by atmospheric entry heating of MMs having either primarily anhydrous and hydrated mineralogy. Therefore, it is difficult to deduce the original mineralogy before entering the Earth's atmosphere. Among them, the SR-XRD pattern of D03IB10 (\#10) indicates that olivine, pyroxene, and pyrrhotite in it are primary coarse-grained phases based on the sharpness of peaks attributed to these minerals, and the coarse-grained minerals shown in Fig. 1 for \#10 support these results. Magnetite in this particle was probably formed during atmospheric entry by decomposition of pyrrhotite on its surface. Because D05IB20 (\#20) has sporadic porous and fine-grained material on its surface, it might have experienced weak to moderate heating. Actually, D03IB05 (\#05), D03IB30 (\#30), and D03IB45 (\#45) have slightly melted and cracked surfaces, suggestive of 

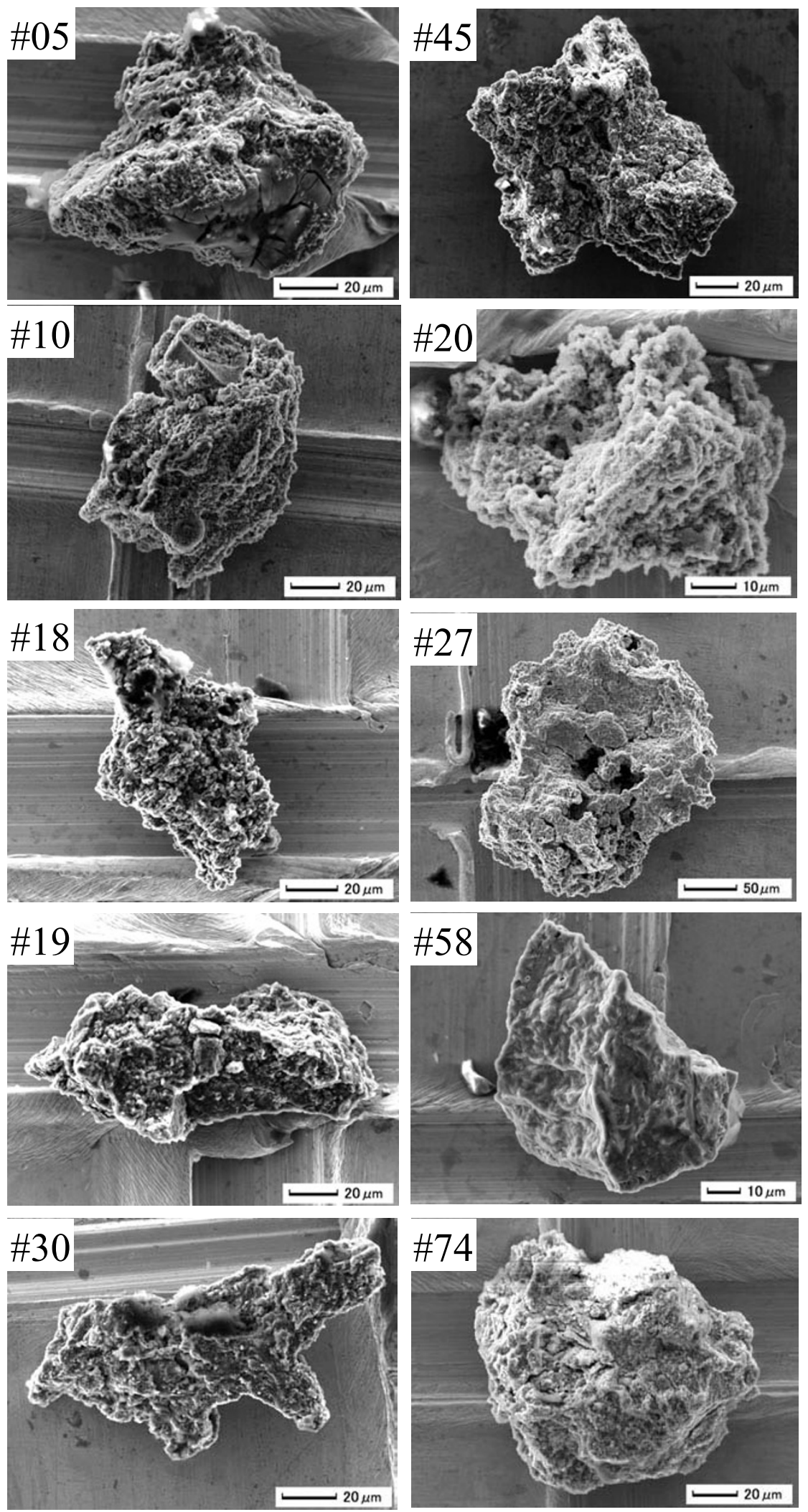

Fig. 1. Secondary electron images of snow-AMMs investigated in this study. The top-left two digits in these pictures are the last two of sample numbers shown in Table 1.

moderate heating; D05IB27 (\#27) is a typical scoriaceous MM that experienced severe heating. Apparently, D05IB58 (\#58) is a fragment that might be composed of olivine and pyrrhotite based on SR-XRD data (Table 1).

Of the samples, D03IB19 (\#19) is the only MM showing no marked diffraction peaks (Table 1). The amorphous material in \#19 must not have been formed by moderate heating (ca. $700^{\circ} \mathrm{C}$ ) of phyllosilicates because such MMs generally contain abundant magnetite. Therefore, sample \#19 might have been composed mainly of poorly crystalline 
Table 1. List of Antarctic micrometeorites studied in this work.

\begin{tabular}{|c|c|c|c|c|c|}
\hline $\begin{array}{l}\text { Sample } \\
\text { No. }\end{array}$ & & $\begin{array}{l}\text { size } \\
\mu \mathrm{m}\end{array}$ & $\begin{array}{c}\text { Weight } \\
\mu \mathrm{g}\end{array}$ & Mineral composition & $\begin{array}{c}\text { SEM chemical } \\
\text { composition }\end{array}$ \\
\hline$\overline{\text { D03IB05 }}$ & 114 & $\times 96$ & $0.83 \pm 0.12$ & Olivine, Pyroxene, Pyrrhotite and Magnetite & Chondritic \\
\hline D03IB10 & 113 & $\times 81$ & $0.33 \pm 0.15$ & Olivine, Pyroxene, Pyrrhotite and Magnetite (anhydrous) & Al-poor \\
\hline D03IB18 & 112 & $\times 73$ & $0.26 \pm 0.20$ & Olivine, Pyroxene, Pyrrhotite, Magnetite and Magnesio-wustite & Chondritic \\
\hline D03IB19 & 147 & $\times 66$ & $0.14 \pm 0.18$ & Amorphous-rich & Ca-poor \\
\hline D03IB30 & 143 & $\times 68$ & not measured & Olivine, Pyrrhotite and Magnetite & C-rich \\
\hline D03IB45 & 131 & $\times 109$ & $0.48 \pm 0.18$ & Olivine, Pyroxene, Pyrrhotite and Magnetite & Chondritic \\
\hline D05IB20 & 84 & $\times 67$ & $0.42 \pm 0.12$ & Olivine, Pyroxene, Pyrrhotite and Magnetite & Ca-poor \\
\hline D05IB27 & 276 & $\times 214$ & $18.5 \pm 0.24$ & Olivine, Pyrrhotite and Magnetite & Chondritic \\
\hline D05IB58 & 87 & $\times 66$ & $0.21 \pm 0.09$ & Olivine, Pyrrhotite and Magnetite & Ca-poor \\
\hline D05IB74 & 130 & $\times 119$ & $1.03 \pm 0.15$ & Olivine, Pyrrhotite, Magnetite and Saponite (hydrated) & Chondritic \\
\hline
\end{tabular}

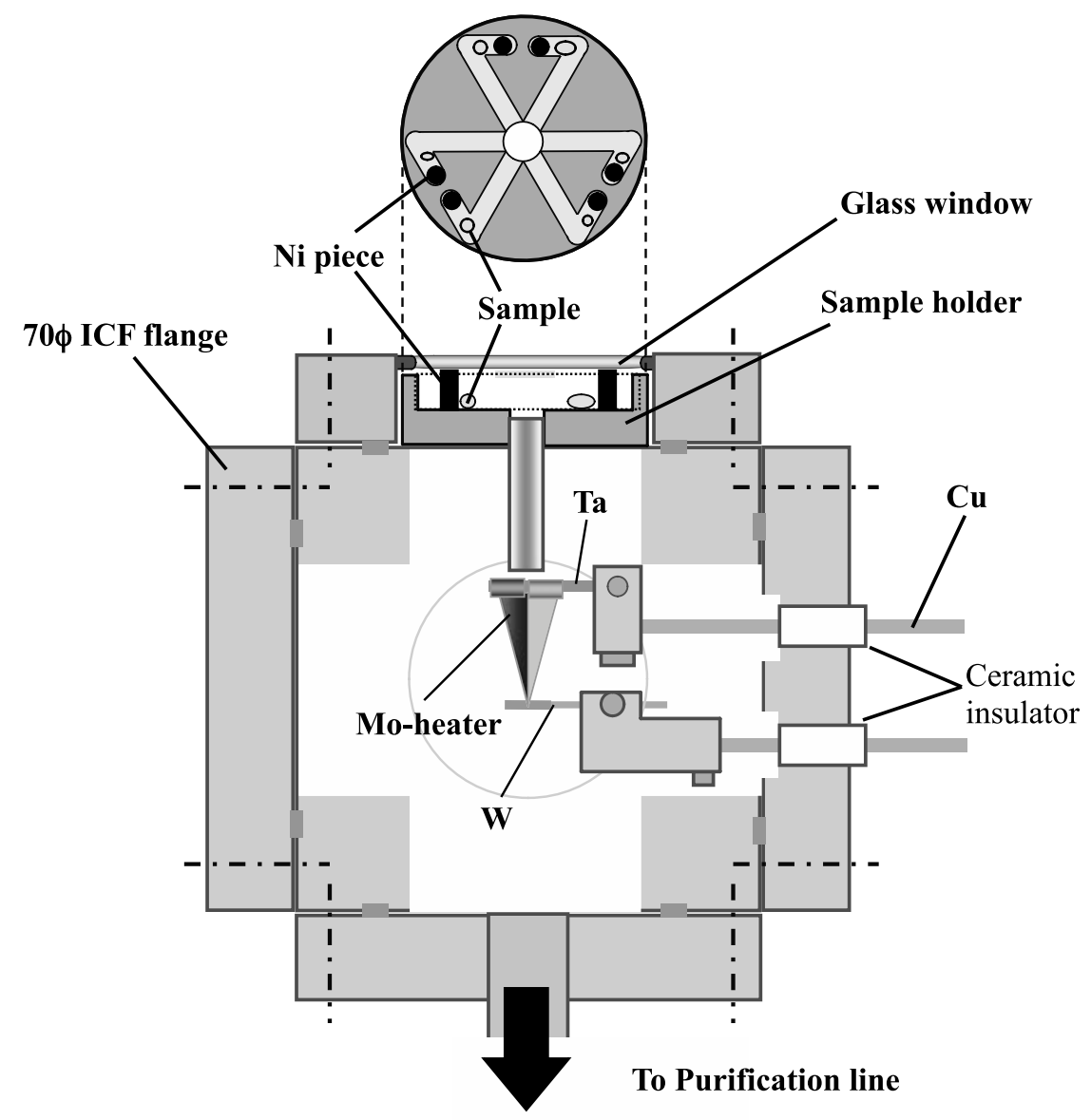

Fig. 2. Schematic diagram of the miniature furnace used in this study. Six samples wrapped in Al-foil can be loaded with Ni-pieces in the sample holder, which is placed on the furnace. Each sample to be measured is dropped into Mo-heater by manipulating the Ni-piece with a small magnet. Electric power is applied to the heater results in the temperature indicated by the calibration curve shown in Fig. 3 . The bottom flange is connected to the purification line of the mass spectrometer system (modified-VG5400/MS-III). Materials aside from those specified are SUS304.

material before atmospheric entry and experienced weak heating.

\subsection{Low blank miniature furnace}

We manufactured a miniature furnace equipped with a small electrical resistance heater to extract noble gases from small samples by stepwise heating. A schematic diagram of the furnace is presented in Fig. 2. The handmade heater is made of Mo-foil ( $0.025 \mathrm{~mm}$ thick) and its shape and size are, respectively, quadrangular pyramidal and about $4 \times$ $4 \times 20 \mathrm{~mm}$. The heater is supported in a stainless steel (SUS 304$)$ vacuum chamber by a Ta-wire $(0.5 \mathrm{~mm}$ diam- eter) at the upper side and a $\mathrm{W}$-wire $(0.4 \mathrm{~mm}$ diameter $)$ at the bottom. The wires were connected to $\mathrm{Cu}$-rods of a $70 \phi \mathrm{ICF}$ feed-through. A small portion at the bottom of the heater becomes hot depending on input electric power applied using a computer-controlled current-voltage power supply. An example of calibration curve of temperature versus input electric power are presented in Fig. 3. The curve is calibrated when the heater is renewed. The temperature was measured using an optical pyrometer because even a thin thermocouple attached to the heater decreases the temperature considerably as a result of thermal conductivity, 


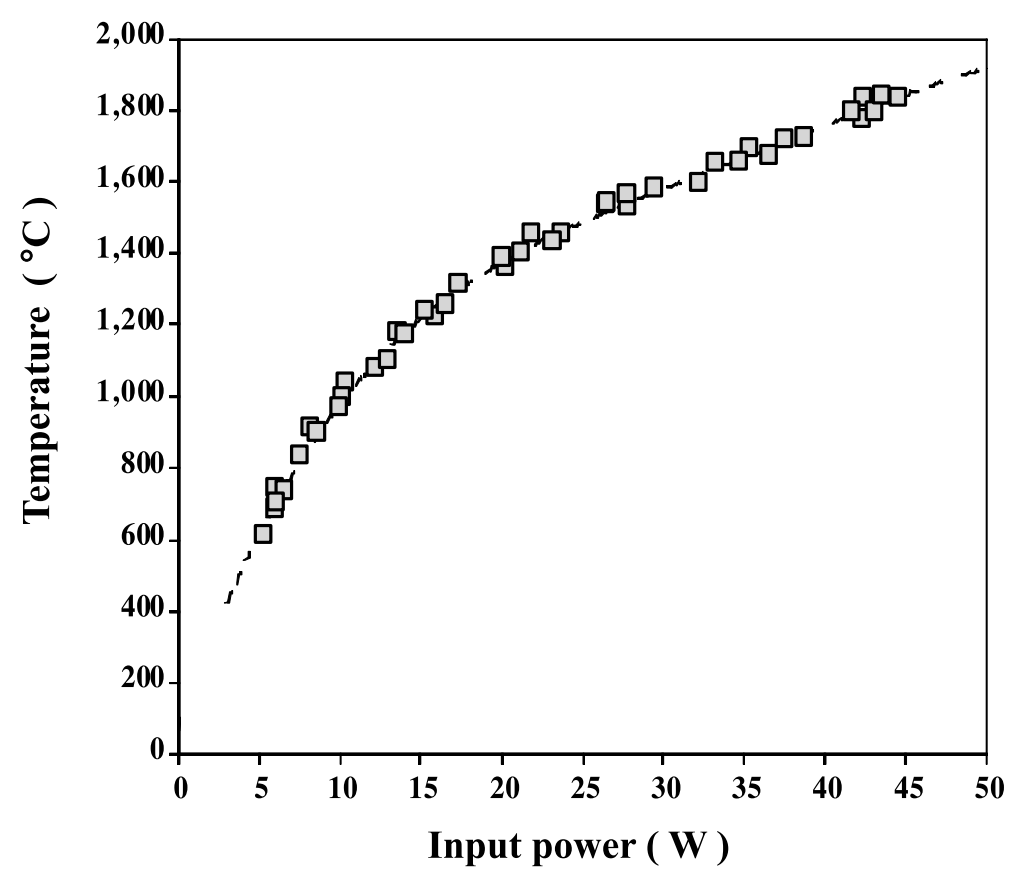

Fig. 3. Temperature of the Mo-heater (Fig. 2) versus applied electric power. Temperature of the heater $\left({ }^{\circ} \mathrm{C}\right)$ was measured using an optical pyrometer. Electric power (W) is supplied with a computer-controlled power supply (N5744A; Agilent Tech.).

resulting in lowered maximum temperature. Heater temperatures of $600-1800^{\circ} \mathrm{C}$ are controllable by application of electric power of 5-40 W (ca. $16 \mathrm{~A}$ and ca. $2.5 \mathrm{~V}$ ). We estimate the input power to attain lower heating temperature $\left(<600^{\circ} \mathrm{C}\right)$ by extrapolating the calibration curve. The time necessary to reach the target temperature $\left(\leq 800^{\circ} \mathrm{C}\right)$ from room temperature is about $30 \mathrm{~s}$, and about $120 \mathrm{~s}$ up to $1600^{\circ} \mathrm{C}$. Although the temperature can be increased to $1900^{\circ} \mathrm{C}$, the heater lifetime becomes very short because of evaporation of Mo.

\subsection{Procedure of noble gas analysis}

Sample masses were measured using an electric microbalance capable of measuring masses as small as $0.1 \mu \mathrm{g}$. First, a piece of Al-foil (6 $\mu \mathrm{m}$ thick) weighing 200-300 $\mu \mathrm{g}$ was measured several times; then a sample was wrapped in the Al-foil and weighed several times. The sample mass was calculated by subtracting the average mass of the empty Al-foil from the average of the wrapped sample. Masses of the samples were 0.14-18.5 $\mu \mathrm{g}$ (Table 1), and the errors were calculated by combining both uncertainties statistically. We were not able to calculate the mass of sample \#30 because Al-foil was partly lost after wrapping the sample.

Six samples wrapped in Al-foil were loaded in a sample holder, as shown in Fig. 2. The sample holder was designed originally by R. Okazaki (personal communication), and improved later in our laboratory. The sample holder was attached to the upper part of the miniature furnace and connected to a noble gas purification line. A modified VG5400/MS-III mass spectrometer system at the Geochemical Research Center, The University of Tokyo, was used for noble gas analyses. The samples were pre-heated in ultra high vacuum at $150^{\circ} \mathrm{C}$ for about one day to remove atmospheric contamination. For noble gas extraction, each sample to be measured was dropped into the Mo-heater of the miniature furnace. Stepwise heating was applied to all the snow-AMMs at $400,500,600,700,800$, and $1600^{\circ} \mathrm{C}$. Each sample was heated to the intended temperature (400, $500,600,700$, and $800^{\circ} \mathrm{C}$ ) from room temperature in $30 \mathrm{~s}$, the input power maintained for $3 \mathrm{~min}$, followed by decrease to room temperature. It took $120 \mathrm{~s}$, however, to increase the temperature to $1600^{\circ} \mathrm{C}$, which was then maintained for $5 \mathrm{~min}$. The samples were not melted at temperatures up to $800^{\circ} \mathrm{C}$, but melted at $1600^{\circ} \mathrm{C}$. Noble gases released from the samples at each temperature step were purified using a Ti-Zr getter and two getter pumps (NP10; SAES Getters S.p.A.). In each extraction temperature step of $400-800^{\circ} \mathrm{C}$, $\mathrm{Ar}, \mathrm{Kr}$, and Xe were adsorbed onto a charcoal trap cooled to liquid nitrogen temperature; then $\mathrm{Ne}$ was adsorbed onto a cryogenically cooled sintered stainless-steel trap (cryo-trap) at $20 \mathrm{~K}$. Helium was analyzed first. Next, Ne was desorbed from the cryo-trap at $60 \mathrm{~K}$ and measured. Lastly, $\mathrm{Ar}, \mathrm{Kr}$, and Xe were desorbed from the charcoal trap, and abundances of ${ }^{40} \mathrm{Ar},{ }^{84} \mathrm{Kr}$ and ${ }^{132} \mathrm{Xe}$, and $\mathrm{Ar}$ isotopic ratios were measured. For the $1600^{\circ} \mathrm{C}$ fraction, $\mathrm{Ne}, \mathrm{Ar}, \mathrm{Kr}$, and $\mathrm{Xe}$ were absorbed onto the cryo-trap, leaving only $\mathrm{He}$ in gas phase. After $\mathrm{He}$ analysis, $\mathrm{Ne}, \mathrm{Ar}, \mathrm{Kr}$, and $\mathrm{Xe}$ were measured respectively by desorbing them successively from the trap at $60,115,155$, and $230 \mathrm{~K}$. Therefore, isotopic ratios of $\mathrm{Kr}$ and $\mathrm{Xe}$ were measured only for the $1600^{\circ} \mathrm{C}$ fraction. Sensitivities and mass discrimination correction factors of the mass spectrometer were determined by measuring known amounts of atmospheric noble gases and a ${ }^{3} \mathrm{He}-{ }^{4} \mathrm{He}$ mixture with ${ }^{3} \mathrm{He} /{ }^{4} \mathrm{He}=1.71 \times 10^{-4}$. Uncertainty in ${ }^{3} \mathrm{He} /{ }^{4} \mathrm{He}$ ratio of the mixture is estimated to be $\approx 1 \%$ (Nagao et al., 2010). Blank corrections were applied to noble gas data. Typical blank levels for ${ }^{4} \mathrm{He},{ }^{20} \mathrm{Ne},{ }^{36} \mathrm{Ar},{ }^{84} \mathrm{Kr}$, and ${ }^{132} \mathrm{Xe}$ at $1600^{\circ} \mathrm{C}$ are depicted in Fig. 4 with some previously reported values for similar works for comparison. The blank levels in our experiment are as low as those by Hohenberg 


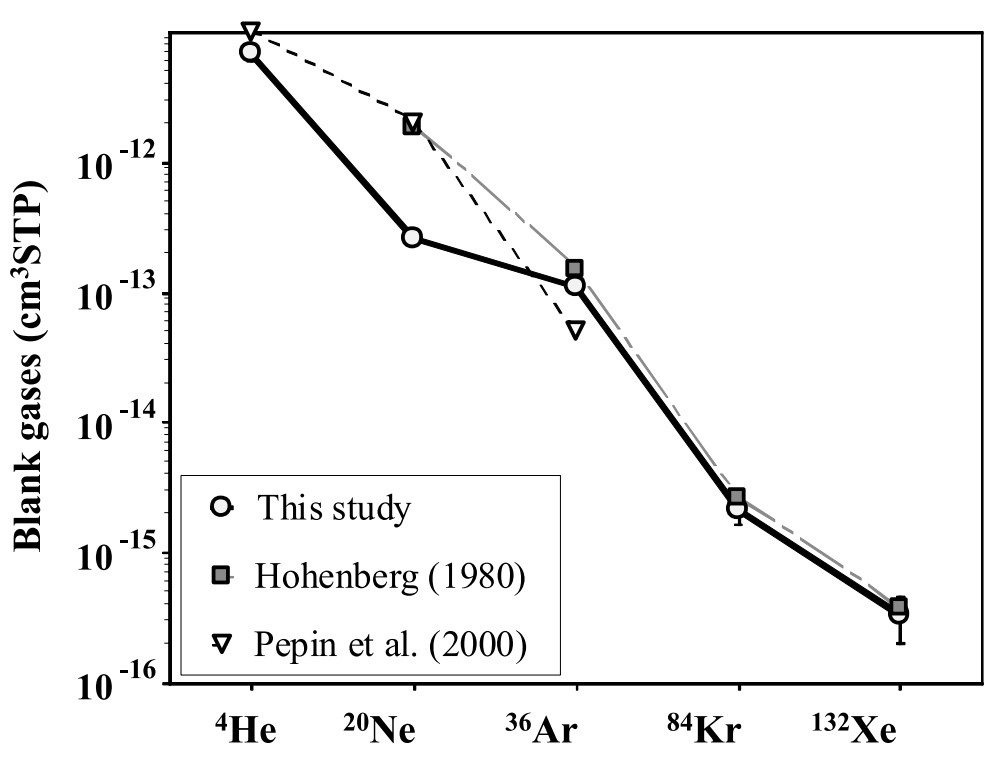

Fig. 4. Blank levels of the MS-III noble gas analyzing system when the miniature furnace was operated at $1600^{\circ} \mathrm{C}$. Reported values using a W-basket heater (Hohenberg, 1980) and a heater made of Ta-foil or Pt-foil (Pepin et al., 2000) are presented for comparison.

(1980) with a W-wire basket and by Pepin et al. (2000) with Ta-foil or Pt-foil.

\section{Results and Discussion}

Concentrations of $\mathrm{He}, \mathrm{Ne}, \mathrm{Ar},{ }^{84} \mathrm{Kr}$, and ${ }^{132} \mathrm{Xe}$, and isotopic ratios of $\mathrm{He}, \mathrm{Ne}$, and $\mathrm{Ar}$ for nine snow-AMMs are presented in Table 2. Isotopic ratios of $\mathrm{Kr}$ and $\mathrm{Xe}$ measured for the fraction at $1600^{\circ} \mathrm{C}$ are listed in Tables 3 and 4 , respectively. Experimental errors for isotopic ratios are $1 \sigma$, including uncertainties in blank correction. Errors for noble gas concentrations include experimental uncertainties related to noble gas abundances and blank corrections. Because of the small absolute amounts of noble gases extracted from the tiny particles, the amounts were comparable with blank levels in some cases. In such cases, concentrations and/or isotopic ratios could not be determined. In the isotopic analysis of $\mathrm{Kr}$ and $\mathrm{Xe}$, measurements of minor isotopes ${ }^{78} \mathrm{Kr},{ }^{124} \mathrm{Xe}$, and ${ }^{126} \mathrm{Xe}$ were skipped to allocate time to analyze major isotopes. Sample \#58 was dropped into the furnace unintentionally with the Ni piece and both were heated in the furnace. For this reason, released amounts of noble gases were large and isotopic ratios closely resembled those of the terrestrial atmosphere. Consequently, noble gas data for this sample were not presented in the tables.

The ${ }^{3} \mathrm{He} /{ }^{4} \mathrm{He}$ ratios for all the samples are in the range $(2.3-4.4) \times 10^{-4}$, which are between SW-He, i.e. ${ }^{3} \mathrm{He} /{ }^{4} \mathrm{He}$ $=(4.64 \pm 0.09) \times 10^{-4}$ (Heber et al., 2009), $(4.4 \pm 0.2) \times$ $10^{-4}$ (Grimberg et al., 2008), and $(4.34 \pm 0.02) \times 10^{-4}$ (Mabry et al., 2007), and He in Jupter's atmosphere, $(1.66 \pm 0.06) \times 10^{-4}$ (Mahaffey et al., 1998). The latter is thought to resemble He in protoplanetary nebula. The low ${ }^{3} \mathrm{He} /{ }^{4} \mathrm{He}$ ratios observed in snow-AMMs, however, may not be the He in protoplanetary nebula trapped in them, but a fractionated SW-He implanted into relatively deep interior of the grains, survived from heating upon Earth's atmospheric entry.

\subsection{Light noble gases $\mathrm{He}$ and $\mathrm{Ne}$ in the snow-AMMs}

Concentrations and release profiles of ${ }^{4} \mathrm{He}$ depicted in Fig. 5 show wide variations among the measured snowAMMs. The release profiles are classifiable into three groups according to the released abundances of ${ }^{4} \mathrm{He}$, i.e. samples \#10, \#19, \#20, and \#74 with high ${ }^{4} \mathrm{He}$ concentrations (on the order of $10^{-3} \mathrm{~cm}^{3} \mathrm{STP} / \mathrm{g}$ ), samples \#05 and \#45 with medium ${ }^{4} \mathrm{He}$ concentrations $\left(10^{-4} \mathrm{~cm}^{3} \mathrm{STP} / \mathrm{g}\right)$, and samples \#18, \#27, and \#30 with low ${ }^{4} \mathrm{He}$ concentrations $\left(10^{-5} \mathrm{~cm}^{3} \mathrm{STP} / \mathrm{g}\right)$. In the high ${ }^{4} \mathrm{He}$ group, the release profiles generally differ from each other, with \#10 showing a release pattern more similar to the medium and low ${ }^{4} \mathrm{He}$ concentration samples, where almost all gas was released only at $1600^{\circ} \mathrm{C}$. The high temperature He release has ${ }^{3} \mathrm{He} /{ }^{4} \mathrm{He}$ ratios of $(2.6-3.0) \times 10^{-4}$, much lower than the value of $4.64 \times 10^{-4}$ for SW-He (Heber et al., 2009). The release profiles and the ${ }^{3} \mathrm{He} /{ }^{4} \mathrm{He}$ ratios for these samples indicate only a small fraction of deeply implanted solar He was retained in these samples. Mineralogical observations also suggest moderate or severe heating for these snow-AMMs, as noted above.

Sample \#20 released a large amount of ${ }^{4} \mathrm{He}, 7.4 \times 10^{-3}$ $\mathrm{cm}^{3} \mathrm{STP} / \mathrm{g}$, at the low temperature of $500^{\circ} \mathrm{C}$, with a subsequent sharp decrease at higher temperatures. These observations are consistent with the weak to moderate heating implied from the presence of porous and fine-grained material on the surface of \#20. The release profile suggests a slow entry speed into the atmosphere and a heating temperature less than $500^{\circ} \mathrm{C}$ for this sample. The total ${ }^{4} \mathrm{He}$ concentration of this sample is as high as $1.5 \times 10^{-2} \mathrm{~cm}^{3} \mathrm{STP} / \mathrm{g}$; its ${ }^{4} \mathrm{He} /{ }^{20} \mathrm{Ne}$ ratio is unusually high, as discussed in the next section. Sample \#74 released more ${ }^{4} \mathrm{He}$ at $400^{\circ} \mathrm{C}$ than $\# 20$, which indicates a heating temperature less than that of \#20. This is consistent with the estimated low temperature, $<600^{\circ} \mathrm{C}$, deduced from the preservation of saponite in this snow-AMM. Although sample \#19 has experienced a higher temperature (up to $600-700^{\circ} \mathrm{C}$ ), the amount of ${ }^{4} \mathrm{He}$ released at $700^{\circ} \mathrm{C}$ is similar to that of $\# 74$, suggesting iden- 
Table 2. Noble gas concentrations and isotopic ratios of snow Antarctic micrometeorites.

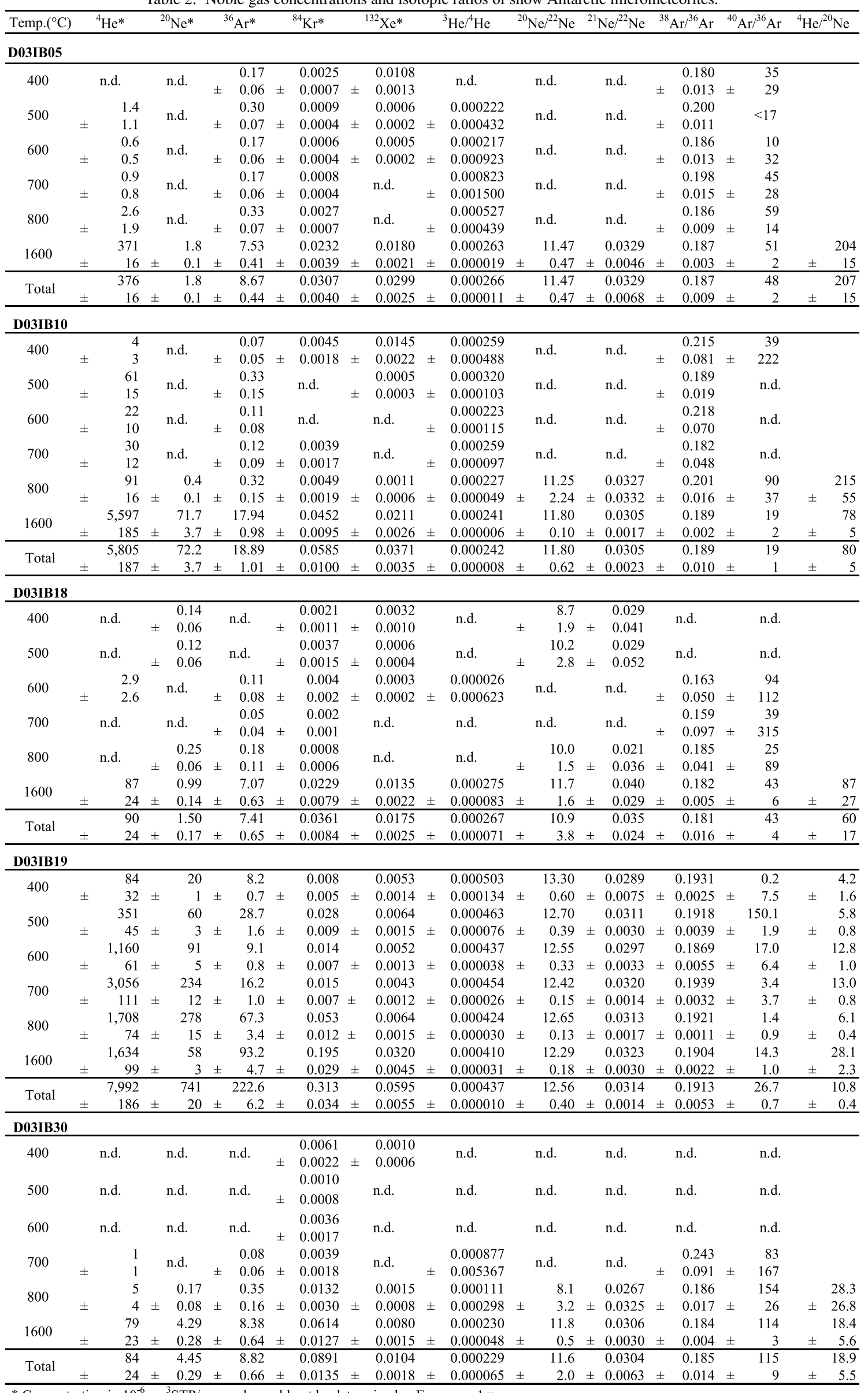


Table 2. (continued).

\begin{tabular}{|c|c|c|c|c|c|c|c|c|c|c|c|c|c|c|c|c|c|c|c|c|c|}
\hline \multirow{2}{*}{$\begin{array}{c}\text { Temp }\left({ }^{\circ} \mathrm{C}\right) \\
\text { D03IB45 }\end{array}$} & \multicolumn{3}{|c|}{${ }^{4} \mathrm{He}^{*}$} & ${ }^{20} \mathrm{Ne}^{*}$ & \multicolumn{3}{|c|}{${ }^{36} \mathrm{Ar}^{*}$} & \multicolumn{2}{|l|}{${ }^{84} \mathrm{Kr}^{*}$} & \multicolumn{2}{|l|}{${ }^{132} \mathrm{Xe}^{*}$} & \multirow[t]{2}{*}{${ }^{3} \mathrm{He} /{ }^{4} \mathrm{He}$} & \multicolumn{2}{|c|}{${ }^{20} \mathrm{Ne} /{ }^{22} \mathrm{Ne}$} & & $\mathrm{Ne} /{ }^{22} \mathrm{Ne}$ & & $\mathrm{Ar} /^{36} \mathrm{Ar}$ & & $\mathrm{Ar} /{ }^{36} \mathrm{Ar}$ & ${ }^{4} \mathrm{He} /{ }^{20} \mathrm{Ne}$ \\
\hline & & & & & & & & & & & & & & & & & & & & & \\
\hline 400 & & 92 & & 0.04 & & 0.03 & & 0.0031 & & 0.0020 & & d & & 9.32 & & 0.0352 & & 0.190 & & 182.1 & 2094 \\
\hline 400 & \pm & 11 & \pm & 0.03 & \pm & 0.03 & \pm & 0.0010 & \pm & 0.0006 & & n.d. & \pm & 2.99 & \pm & 0.0583 & \pm & 0.086 & \pm & 124.2 & \pm 1426 \\
\hline 500 & & 2 & & 0.28 & & 0.17 & & 0.0025 & & 0.0011 & & nd & & 12.29 & & 0.0371 & & 0.170 & & $<44$ & 7.4 \\
\hline 500 & \pm & 2 & \pm & 0.04 & \pm & 0.08 & \pm & 0.0009 & \pm & 0.0004 & & n.d. & \pm & 2.18 & \pm & 0.0234 & \pm & 0.015 & & $<44$ & 6.3 \\
\hline & & 3 & & 0.26 & & 0.26 & & 0.0009 & & 0.0000 & & 0.000236 & & 9.91 & & 0.0181 & & 0.198 & & 4.9 & 13.2 \\
\hline 000 & \pm & 3 & \pm & 0.04 & \pm & 0.10 & \pm & 0.0005 & \pm & 0.0000 & \pm & 0.000267 & \pm & 1.22 & \pm & 0.0178 & \pm & 0.015 & \pm & 37.1 & $\pm \quad 10.4$ \\
\hline 700 & & 5 & & 0.14 & & 0.32 & & 0.0013 & & nd & & 0.000147 & & 11.90 & & 0.0286 & & 0.188 & & $<$ & 39.2 \\
\hline 100 & \pm & 4 & \pm & 0.03 & \pm & 0.11 & \pm & 0.0007 & & n.d. & \pm & 0.000197 & \pm & 2.70 & \pm & 0.0464 & \pm & 0.009 & & $<22$ & $\pm \quad 28.2$ \\
\hline 800 & & 15 & & 0.44 & & 0.62 & & 0.0047 & & 0.0005 & & 0.000191 & & 10.00 & & 0.0261 & & 0.184 & & 29.7 & 34.9 \\
\hline 800 & \pm & 7 & \pm & 0.04 & \pm & 0.13 & \pm & 0.0012 & \pm & 0.0003 & \pm & 0.000093 & \pm & 0.75 & \pm & 0.0137 & \pm & 0.006 & \pm & 14.1 & $\pm \quad 15.5$ \\
\hline & & 818 & & 48.73 & & 21.05 & & 0.0404 & & 0.0143 & & 0.000259 & & 11.65 & & 0.0318 & & 0.191 & & 7.0 & 16.8 \\
\hline 1600 & \pm & 32 & \pm & 2.54 & \pm & 1.08 & \pm & 0.0067 & \pm & 0.0018 & \pm & 0.000015 & \pm & 0.12 & \pm & 0.0015 & \pm & 0.003 & \pm & 1.3 & 1.1 \\
\hline Total & & 936 & & 49.89 & & 22.46 & & 0.0529 & & 0.0179 & & 0.000239 & & 11.63 & & 0.0317 & & 0.191 & & 7.5 & $\overline{18.8}$ \\
\hline rotal & \pm & 35 & \pm & 2.54 & \pm & 1.10 & \pm & 0.0070 & \pm & 0.0020 & \pm & 0.000009 & \pm & 0.60 & \pm & 0.0022 & \pm & 0.009 & \pm & 0.4 & 1.2 \\
\hline D05IB20 & & & & & & & & & & & & & & & & & & & & & \\
\hline 400 & & 242 & & 0.16 & & & & 0.0029 & & $n d$ & & 0.000337 & & 12.25 & & 0.009 & & & & nd & 1504 \\
\hline 400 & \pm & 17 & \pm & 0.12 & & n.d. & \pm & 0.0007 & & n.d. & \pm & 0.000056 & \pm & 7.67 & \pm & 0.135 & & n.d. & & n.d & 1122 \\
\hline 500 & & 7,350 & & 2.15 & & 0.08 & & 0.0024 & & & & 0.000356 & & 10.92 & & 0.025 & & 0.197 & & & 3412 \\
\hline 500 & \pm & 307 & \pm & 0.15 & \pm & 0.05 & \pm & 0.0006 & & & \pm & 0.000057 & \pm & 1.30 & \pm & 0.012 & \pm & 0.042 & & 1.d. & 275 \\
\hline 600 & & 3,148 & & 1.34 & & nd & & 0.0011 & & $n d$ & & 0.000330 & & 12.30 & & 0.046 & & $n d$ & & $n$ & 2350 \\
\hline & \pm & 132 & \pm & 0.13 & & n.d. & \pm & 0.0004 & & & \pm & 0.000014 & \pm & 2.03 & \pm & 0.016 & & n.a. & & n. & 255 \\
\hline 700 & & 1,760 & & 1.84 & & $n . d$. & & 0.0014 & & & & 0.000366 & & 11.66 & & 0.041 & & $\mathrm{nd}$ & & $n d$ & 957 \\
\hline 100 & \pm & 144 & \pm & 0.14 & & n.d. & \pm & 0.0005 & & & \pm & 0.000023 & \pm & 1.26 & \pm & 0.023 & & n.a. & & n.d. & 108 \\
\hline 800 & & 1,373 & & 4.49 & & 0.08 & & 0.0037 & & $n$ & & 0.000374 & & 11.86 & & 0.030 & & 0.159 & & 181 & 306 \\
\hline 800 & \pm & 57 & \pm & 0.20 & \pm & 0.06 & \pm & 0.0008 & & $n$ & \pm & 0.000020 & \pm & 0.68 & \pm & 0.010 & \pm & 0.047 & \pm & 34 & 19 \\
\hline 1600 & & 2,571 & & 19.45 & & 1.36 & & 0.0070 & & 0.0023 & & 0.000357 & & 11.95 & & 0.036 & & 0.194 & & 65 & 132 \\
\hline 1000 & \pm & 110 & \pm & 0.59 & \pm & 0.27 & \pm & 0.0030 & \pm & 0.0009 & \pm & 0.000016 & \pm & 0.36 & \pm & 0.023 & \pm & 0.006 & \pm & 15 & 7 \\
\hline Total & & 16,443 & & 29.44 & & 1.52 & & 0.0185 & & 0.0023 & & 0.000354 & & 11.83 & & 0.035 & & 0.193 & & 72 & 559 \\
\hline Iotal & \pm & 385 & \pm & 0.68 & \pm & 0.28 & \pm & 0.0033 & \pm & 0.0009 & \pm & 0.000008 & \pm & 0.63 & \pm & 0.015 & \pm & 0.036 & \pm & 13 & 18 \\
\hline D05IB2 & & & & & & & & & & & & & & & & & & & & & \\
\hline 400 & & 0.2 & & $n$ & & 0.003 & & 0.00034 & & 0.00058 & & 0.000262 & & nd & & nd & & 0.200 & & 178 & \\
\hline & \pm & 0.1 & & 11.0 & & 0.002 & \pm & 0.00005 & \pm & 0.00004 & \pm & 0.000272 & & & & & \pm & 0.027 & \pm & 42 & \\
\hline 500 & & 0.3 & & n.d. & & 0.003 & & 0.00001 & & 0.00005 & & 0.000179 & & nd. & & $\mathrm{n}$ & & 0.188 & & 81 & \\
\hline 500 & \pm & 0.1 & & n.d. & \pm & 0.002 & \pm & 0.00001 & \pm & 0.00001 & \pm & 0.000247 & & n.d. & & & \pm & 0.020 & \pm & 93 & \\
\hline 600 & & 0.3 & & $n d$. & & 0.005 & & 0.00002 & & 0.00004 & & 0.000144 & & $\mathrm{~d}$ & & $n d$ & & 0.192 & & $<41$ & \\
\hline & \pm & 0.1 & & & & 0.002 & \pm & 0.00001 & \pm & 0.00001 & \pm & 0.000153 & & & & & \pm & 0.016 & & & \\
\hline 700 & & 0.6 & & n.d. & & 0.011 & & 0.00002 & & 0.00001 & & 0.000145 & & nd & & nd & & 0.192 & & 22 & \\
\hline 100 & \pm & 0.2 & & n1.d. & \pm & 0.003 & \pm & 0.00001 & \pm & 0.00000 & \pm & 0.000086 & & 11. & & & \pm & 0.012 & \pm & 28 & \\
\hline & & 1.8 & & 0.016 & & 0.023 & & 0.00005 & & 0.00002 & & 0.000299 & & 11.32 & & 0.0473 & & 0.196 & & 24 & 117.6 \\
\hline 800 & \pm & 0.2 & \pm & 0.003 & \pm & 0.004 & \pm & 0.00002 & \pm & 0.00001 & \pm & 0.000075 & \pm & 2.26 & \pm & 0.0416 & \pm & 0.005 & \pm & 9 & $\pm \quad 26.5$ \\
\hline 1600 & & 37.2 & & 0.972 & & 0.404 & & 0.00179 & & 0.00162 & & 0.000295 & & 12.17 & & 0.0302 & & 0.192 & & 18 & 38.3 \\
\hline 1000 & \pm & 1.6 & \pm & 0.029 & \pm & 0.041 & \pm & 0.00032 & \pm & 0.0 & \pm & 0.000016 & \pm & 0.26 & \pm & 0. & \pm & 0.002 & \pm & 3 & 2.0 \\
\hline Total & & 40.3 & & 0.988 & & 0.450 & & 0.00222 & & 0.00232 & & 0.000291 & & 12.15 & & 0.0305 & & 0.192 & & 20 & 40.9 \\
\hline 1 otal & \pm & 1.7 & \pm & 0.029 & \pm & 0.041 & \pm & 0.00033 & \pm & 0.00013 & \pm & 0.000012 & \pm & 0.42 & \pm & 0.0036 & \pm & 0.018 & \pm & 2 & 2.1 \\
\hline D05I & & & & & & & & & & & & & & & & & & & & & \\
\hline & & 2,704 & & 47.3 & & 0.98 & & 0.0015 & & 03 & & 18 & & 12.27 & & & & 939 & & 0.0 & 57.1 \\
\hline & \pm & 113 & \pm & 1.4 & \pm & 0.11 & \pm & 0.0003 & \pm & 0.0001 & \pm & 0.000021 & \pm & 0.12 & \pm & 0.0018 & \pm & 0.0052 & \pm & 2.8 & 2.9 \\
\hline 500 & & 5,119 & & 68.0 & & 1.39 & & 0.0012 & & 0.0001 & & 0.000419 & & 12.31 & & 0.0313 & & 0.1954 & & & 75.3 \\
\hline 500 & \pm & 214 & \pm & 2.0 & \pm & 0.15 & \pm & 0.0003 & \pm & 0.0001 & \pm & 0.000015 & \pm & 0.08 & \pm & 0.0019 & \pm & 0.0039 & & & 3.8 \\
\hline & & 4,188 & & 52.7 & & 1.24 & & & & & & 0.000372 & & 12.85 & & 0.0310 & & 0.1923 & & 2.7 & 79.5 \\
\hline 600 & \pm & 175 & \pm & 1.5 & \pm & 0.13 & & . & & $\mathrm{n}$ & \pm & 0.000015 & \pm & 0.17 & \pm & 0.0018 & \pm & 0.0030 & \pm & 2.2 & 4.0 \\
\hline 700 & & 2,779 & & 58.5 & & 2.78 & & & & & & 0.000374 & & 12.85 & & 0.0331 & & 0.1926 & & & 47.5 \\
\hline 100 & \pm & 116 & \pm & 1.7 & \pm & 0.28 & & & & & \pm & 0.000010 & \pm & 0.20 & \pm & 0.0019 & \pm & 0.0028 & & 0.2 & 2.4 \\
\hline 800 & & 868 & & 40.9 & & 5.45 & & 0.0054 & & 0.0002 & & 0.000463 & & 12.80 & & 0.0312 & & 0.1933 & & 0.7 & 21.2 \\
\hline & \pm & 222 & \pm & 1.2 & \pm & 0.53 & \pm & 0.0007 & \pm & 0.0001 & \pm & 0.000100 & \pm & 0.18 & \pm & 0.0018 & \pm & 0.0025 & \pm & 0.5 & 5.5 \\
\hline & & 970 & & 33.2 & & 4.17 & & 0.0149 & & 0.0039 & & 0.000346 & & 12.31 & & 0.0319 & & 0.1962 & & 16.9 & 29.2 \\
\hline 16 & \pm & 42 & \pm & 1.0 & \pm & 0.42 & \pm & 0.0022 & \pm & 0.0012 & \pm & 0.000022 & \pm & 0.13 & \pm & 0.0057 & \pm & 0.0012 & \pm & 2.5 & 1.5 \\
\hline & & 16,628 & & 300.7 & & 16.02 & & 0.0230 & & 0.0045 & & 0.000398 & & 12.56 & & 0.0316 & & 0.1941 & & 5.1 & 55.3 \\
\hline & \pm & 392 & \pm & 3.6 & \pm & 0.77 & \pm & 0.0024 & \pm & 0.0012 & \pm & 0.000009 & \pm & 0.16 & \pm & 0.0011 & \pm & 0.0093 & \pm & 0.2 & 1.5 \\
\hline
\end{tabular}

tical concentrations of ${ }^{4} \mathrm{He}$ between them in space. Unlike the other samples aside from $\# 74$, the ${ }^{3} \mathrm{He} /{ }^{4} \mathrm{He}$ ratio of $(4.37 \pm 0.10) \times 10^{-4}$ is close to the SW-He. As described in Section 2.1, this particle is mostly composed of amorphous material. Release patterns for the groups with medium and low $\mathrm{He}$ concentrations are basically identical, i.e. He is releases at the temperatures between 600 and $1600^{\circ} \mathrm{C}$, although small release peaks are observed at $400^{\circ} \mathrm{C}$ for \#45 and $500^{\circ} \mathrm{C}$ for $\# 10$.

Total concentrations of ${ }^{4} \mathrm{He}$ and ${ }^{4} \mathrm{He} /{ }^{20} \mathrm{Ne}$ ratios are depicted in Fig. 6 with the reported data for stratospheric IDPs
(Nier and Schlutter, 1990, 1993; Kehm et al., 2002) and iceAMMs (Osawa and Nagao, 2002; Osawa et al., 2003a) for comparison. The ratios for solar abundance (850; Anders and Grevesse, 1989) and SW (656: Heber et al., 2009) are also indicated. An extraordinarily high ${ }^{4} \mathrm{He} /{ }^{20} \mathrm{Ne}$ ratio of up to 3400 was observed at $500^{\circ} \mathrm{C}$ for the \#20 sample (Table 2). The high ${ }^{4} \mathrm{He} /{ }^{20} \mathrm{Ne}$ ratio can probably be attributed to enhanced release of $\mathrm{He}$ relative to $\mathrm{Ne}$ during stepwise heating, because the total ${ }^{4} \mathrm{He} /{ }^{20} \mathrm{Ne}$ ratio of 560 for this sample is close to SW. Sample \#20 must have experienced weak heating during atmospheric entry, as de- 
Table 3. $\mathrm{Kr}$ isotopic compositions of snow Antarctic micrometeorites extracted at $1600^{\circ} \mathrm{C}$.

\begin{tabular}{|c|c|c|c|c|c|}
\hline Name & ${ }^{84} \mathrm{Kr}^{*}$ & ${ }^{80} \mathrm{Kr} /{ }^{84} \mathrm{Kr}$ & ${ }^{82} \mathrm{Kr} /{ }^{84} \mathrm{Kr}$ & ${ }^{83} \mathrm{Kr} /{ }^{84} \mathrm{Kr}$ & ${ }^{86} \mathrm{Kr} /{ }^{84} \mathrm{Kr}$ \\
\hline \multirow{2}{*}{ D03IB05 } & 0.023 & 0.038 & 0.185 & 0.204 & 0.278 \\
\hline & 0.004 & 0.012 & 0.022 & 0.022 & 0.040 \\
\hline \multirow{2}{*}{ D03IB 10} & 0.045 & 0.044 & 0.213 & 0.225 & 0.339 \\
\hline & $\pm \quad 0.010$ & 0.015 & 0.040 & 0.037 & 0.042 \\
\hline \multirow{2}{*}{ D03IB 18} & 0.023 & 0.042 & 0.160 & 0.224 & 0.328 \\
\hline & $\pm \quad 0.008$ & 0.028 & 0.080 & 0.059 & 0.087 \\
\hline \multirow{2}{*}{ D03IB19 } & 0.195 & 0.038 & 0.191 & 0.202 & 0.306 \\
\hline & $\pm \quad 0.029$ & 0.013 & 0.012 & 0.018 & 0.028 \\
\hline \multirow{2}{*}{ D03IB30 } & 0.061 & 0.043 & 0.183 & 0.196 & 0.315 \\
\hline & 0.013 & 0.012 & 0.033 & 0.030 & 0.045 \\
\hline \multirow{2}{*}{ D03IB45 } & 0.040 & 0.036 & 0.187 & 0.202 & 0.317 \\
\hline & 0.007 & 0.011 & 0.021 & 0.044 & 0.030 \\
\hline \multirow{2}{*}{ D05IB20 } & 0.007 & 0.039 & 0.219 & 0.168 & 0.318 \\
\hline & $\pm \quad 0.003$ & 0.029 & 0.085 & 0.096 & 0.103 \\
\hline \multirow{2}{*}{ D05IB 27} & 0.0018 & 0.037 & 0.204 & 0.206 & 0.320 \\
\hline & \pm 0.0003 & 0.010 & 0.029 & 0.025 & 0.038 \\
\hline \multirow{2}{*}{ D05IB74 } & 0.015 & 0.045 & 0.194 & 0.210 & 0.314 \\
\hline & \pm 0.002 & 0.009 & 0.035 & 0.052 & 0.032 \\
\hline
\end{tabular}

* Concentration in $10^{-6} \mathrm{~cm}^{3} \mathrm{STP} / \mathrm{g}$. Errors are $1 \sigma$.

Table 4. Xe isotopic compositions of snow Antarctic micrometeorites extracted at $1600^{\circ} \mathrm{C}$.

\begin{tabular}{|c|c|c|c|c|c|c|c|c|c|c|c|c|c|c|}
\hline Name & & ${ }^{2} \mathrm{Xe}^{*}$ & ${ }^{128} \mathrm{Y}$ & ${ }^{132} \mathrm{Xe}$ & ${ }^{129} \mathrm{X}$ & ${ }^{132} \mathrm{Xe}$ & ${ }^{130} \mathrm{X}$ & ${ }^{132} \mathrm{Xe}$ & ${ }^{131} \mathrm{X}$ & ${ }^{132} \mathrm{Xe}$ & ${ }^{134} \mathrm{X}$ & ${ }^{132} \mathrm{Xe}$ & ${ }^{136} \mathrm{X}$ & ${ }^{132} \mathrm{Xe}$ \\
\hline \multirow{2}{*}{ D03IB05 } & & 0.0180 & & 0.086 & & 0.972 & & 0.151 & & 0.826 & & 0.388 & & 0.337 \\
\hline & \pm & 0.0021 & \pm & 0.012 & \pm & 0.081 & \pm & 0.027 & \pm & 0.055 & \pm & 0.034 & \pm & 0.055 \\
\hline \multirow{2}{*}{ D03IB10 } & & 0.0211 & & 0.100 & & 1.039 & & 0.146 & & 0.743 & & 0.357 & & 0.313 \\
\hline & \pm & 0.0026 & \pm & 0.024 & \pm & 0.069 & \pm & 0.018 & \pm & 0.083 & \pm & 0.037 & \pm & 0.063 \\
\hline \multirow{2}{*}{ D03IB 18} & & 0.0135 & & 0.094 & & 1.221 & & 0.134 & & 0.962 & & 0.433 & & 0.349 \\
\hline & \pm & 0.0022 & \pm & 0.030 & \pm & 0.073 & \pm & 0.052 & \pm & 0.122 & \pm & 0.162 & \pm & 0.119 \\
\hline \multirow{2}{*}{ D03IB19 } & & 0.0320 & & 0.072 & & 1.029 & & 0.150 & & 0.748 & & 0.400 & & 0.339 \\
\hline & \pm & 0.0045 & \pm & 0.032 & \pm & 0.123 & \pm & 0.035 & \pm & 0.128 & \pm & 0.058 & \pm & 0.114 \\
\hline \multirow{2}{*}{ D03IB30 } & & 0.0080 & & 0.071 & & 0.979 & & 0.182 & & 0.814 & & 0.399 & & 0.345 \\
\hline & \pm & 0.0015 & \pm & 0.045 & \pm & 0.167 & \pm & 0.073 & \pm & 0.200 & \pm & 0.110 & \pm & 0.080 \\
\hline \multirow{2}{*}{ D03IB45 } & & 0.0143 & & 0.059 & & 1.016 & & 0.173 & & 0.805 & & 0.437 & & 0.343 \\
\hline & \pm & 0.0018 & \pm & 0.011 & \pm & 0.095 & \pm & 0.059 & \pm & 0.097 & \pm & 0.083 & \pm & 0.040 \\
\hline \multirow{2}{*}{ D05IB20 } & & 0.0023 & & 0.084 & & 1.023 & & 0.154 & & 0.883 & & 0.373 & & 0.315 \\
\hline & \pm & 0.0009 & \pm & 0.046 & \pm & 0.342 & \pm & 0.075 & \pm & 0.509 & \pm & 0.131 & \pm & 0.111 \\
\hline \multirow{2}{*}{ D05IB27 } & & 0.0016 & & 0.081 & & 0.995 & & 0.143 & & 0.788 & & 0.360 & & 0.312 \\
\hline & \pm & 0.0001 & \pm & 0.013 & \pm & 0.033 & \pm & 0.011 & \pm & 0.036 & \pm & 0.037 & \pm & 0.033 \\
\hline \multirow{2}{*}{ D05IB74 } & & 0.0039 & & 0.096 & & 0.978 & & 0.144 & & 0.714 & & 0.382 & & 0.279 \\
\hline & \pm & 0.0012 & \pm & 0.030 & \pm & 0.119 & \pm & 0.071 & \pm & 0.083 & \pm & 0.087 & \pm & 0.032 \\
\hline
\end{tabular}

* Concentration in $10^{-6} \mathrm{~cm}^{3} \mathrm{STP} / \mathrm{g}$. Errors are $1 \sigma$.

scribed above (in Fig. 5): most solar gases were preserved in thermally weak phases of this particle.

Other samples \#10, \#19, and \#74 also have higher concentrations of ${ }^{4} \mathrm{He}$ more similar to those of IDPs. This clearly indicates that some snow-AMMs investigated in this study have not suffered from weathering, consistent with their short residence time in snow (less than two years).

A plot of ${ }^{20} \mathrm{Ne} /{ }^{22} \mathrm{Ne}$ versus ${ }^{21} \mathrm{Ne} /{ }^{22} \mathrm{Ne}$ is presented in Fig. 7. The Ne isotopic ratios for ice-AMMs by Osawa and Nagao (2002) and Osawa et al. (2003a) are also shown for comparison. Most data points are similar to those of ice-AMMs, located on a fractionation line passing through $\mathrm{SW}-\mathrm{Ne}$. The fractionation is explained as mass separation effect upon SW-Ne implantation by Grimberg et al. (2008). Solar Ne implanted into deeper layer of MMs with mass fractionation favoring heavier isotopes can be retained more tightly, survived from atmospheric entry heating, than the lower energy SW-Ne implanted into the shallower layer.

No data clearly indicates a cosmogenic Ne contribution to the line connecting SW and air beyond error limits. Estimating the upper limit for a cosmogenic ${ }^{21} \mathrm{Ne}$ concentration in samples \#20,\#74, \#19, and \#10 is difficult because of their high concentrations of solar Ne. Concentrations of cosmogenic ${ }^{21} \mathrm{Ne}$ for the samples with low solar $\mathrm{Ne}$ concentrations are less than $3 \times 10^{-9} \mathrm{~cm}^{3} \mathrm{STP} / \mathrm{g}$, which would correspond to a cosmic-ray exposure age less than $1 \mathrm{Myr}$ if the production rate for chondrites is applied. Lifetimes of the snow-AMMs in space might resemble those of iceAMMs, for which the estimated upper limits of cosmogenic ${ }^{21} \mathrm{Ne}$ constrain the cosmic-ray exposure ages to $\leq 1 \mathrm{Myr}$, although exceptionally long exposure ages were implied for a small number of ice-AMMs (e.g. Osawa and Nagao, 2002).

The ${ }^{3} \mathrm{He} /{ }^{4} \mathrm{He}$ versus ${ }^{20} \mathrm{Ne} /{ }^{22} \mathrm{Ne}$ ratios for total $\mathrm{He}$ and $\mathrm{Ne}$ from the snow-AMMs are depicted in Fig. 8. Ice-AMMs from Osawa and Nagao (2002) and Osawa et al. (2003a) are also shown for comparison. Most snow-AMMs are located in the area where many ice-AMMs are plotted. This shows that ${ }^{3} \mathrm{He} /{ }^{4} \mathrm{He}$ ratios are also fractionated along with $\mathrm{Ne}$, suggesting the presence of residual deep-implanted solar $\mathrm{He}$ and $\mathrm{Ne}$ after loss of solar gases implanted in shallow depth of the particles. The relatively high ${ }^{3} \mathrm{He} /{ }^{4} \mathrm{He}$ and ${ }^{20} \mathrm{Ne} /{ }^{22} \mathrm{Ne}$ ratios in \#19 and \#74 suggest a presence of low energy SW in these samples, for which high concentrations of solar $\mathrm{He}$ and $\mathrm{Ne}$ are inferred from the large amounts of ${ }^{4} \mathrm{He}$ released at $700^{\circ} \mathrm{C}$.

\subsection{Heavy noble gases $\mathrm{Ar}, \mathrm{Kr}$ and $\mathrm{Xe}$ in the snow- AMMS}

The Ar isotopic ratios are depicted in Fig. 9; the Ar isotopic ratios for $\mathrm{SW}\left({ }^{38} \mathrm{Ar} /{ }^{36} \mathrm{Ar}=0.183\right.$; Heber et al., 2009), Q (0.187; Busemann et al., 2000), and Earth's atmosphere 


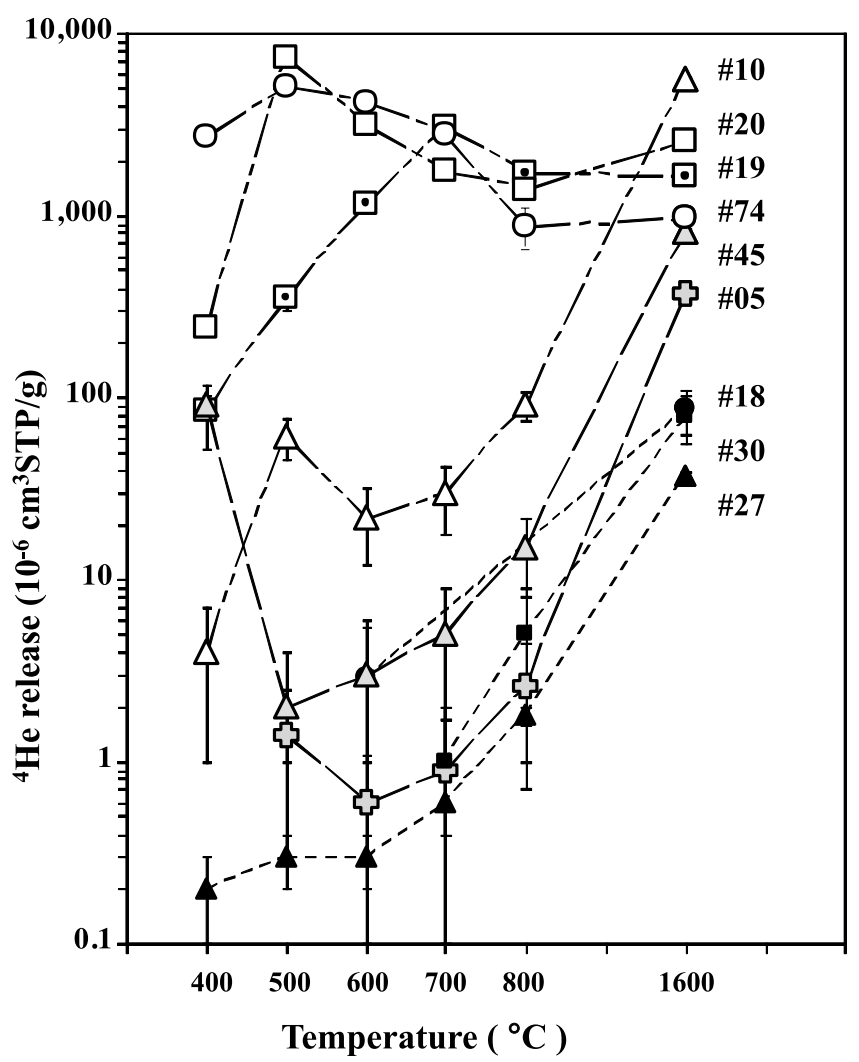

Fig. 5. Release profiles of ${ }^{4} \mathrm{He}$ from individual snow-AMMs measured using stepwise heating at the temperatures of 400, 500, 600, 700,800, and $1600^{\circ} \mathrm{C}$ with the miniature furnace (Fig. 2). The release profiles are separated into three groups according to released amounts of ${ }^{4} \mathrm{He}$; High ${ }^{4} \mathrm{He}$ (on the order of $\left.10^{-3} \mathrm{~cm}^{3} \mathrm{STP} / \mathrm{g}\right)$, Medium ${ }^{4} \mathrm{He}\left(10^{-4} \mathrm{~cm}^{3} \mathrm{STP} / \mathrm{g}\right)$, and Low ${ }^{4} \mathrm{He}\left(10^{-5} \mathrm{~cm}^{3} \mathrm{STP} / \mathrm{g}\right)$. Errors are $1 \sigma$.

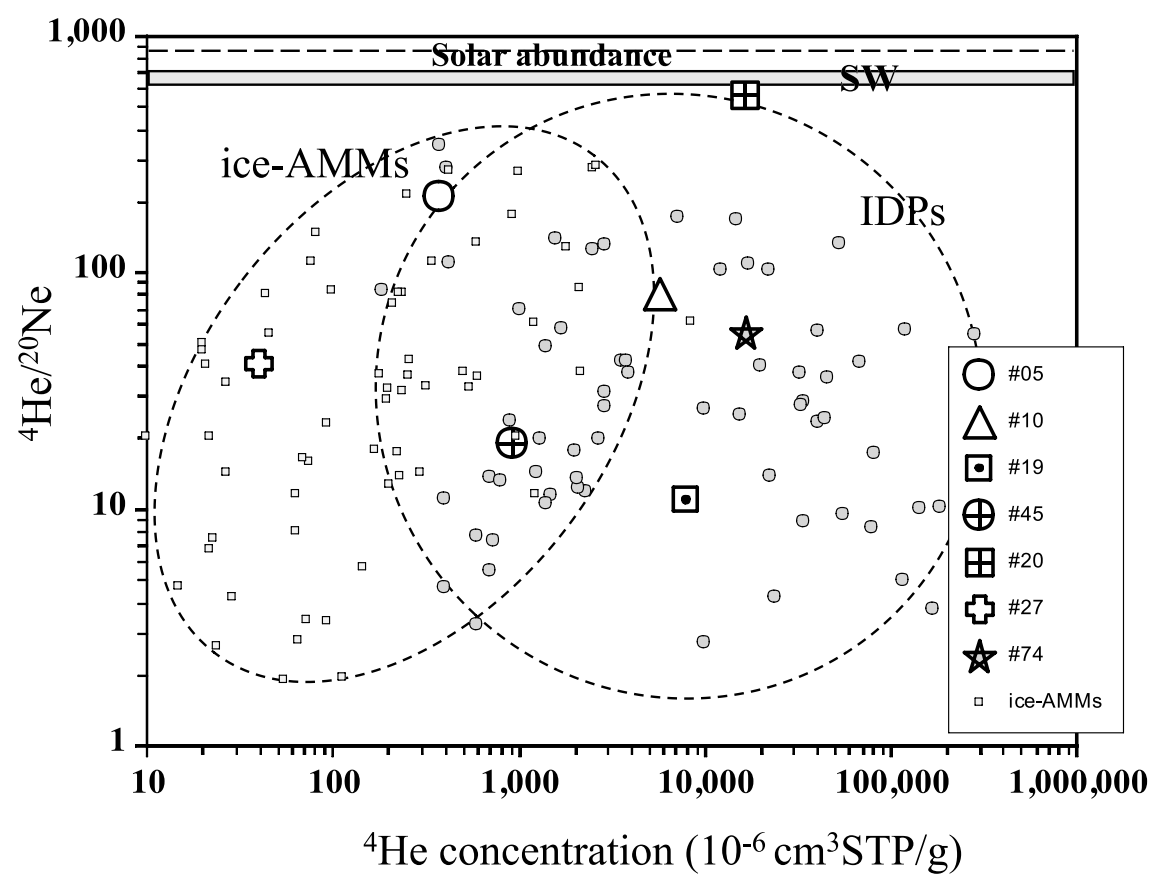

Fig. 6. ${ }^{4} \mathrm{He} /{ }^{20} \mathrm{Ne}$ versus ${ }^{4} \mathrm{He}$ concentrations for seven snow-AMMs. Data for stratospheric IDPs (Nier and Schlutter, 1990, 1993; Kehm et al., 2002) and ice-AMMs (Osawa and Nagao, 2002; Osawa et al., 2003a) are presented for comparison. The ratios for solar abundance (850: Anders and Grevesse, 1989) and SW (556: Heber et al., 2009) are presented. Error bars are within symbols.

$\left(0.188\right.$ and ${ }^{40} \mathrm{Ar} /{ }^{36} \mathrm{Ar}=296 ;$ Nier, 1950) are also shown. Data for samples \#18 and \#30 are omitted because of the large experimental errors. Most data points may be explained as a mixture between atmospheric Ar and Ar with low ${ }^{40} \mathrm{Ar} /{ }^{36} \mathrm{Ar}(\leq 0.1)$ and ${ }^{38} \mathrm{Ar} /{ }^{36} \mathrm{Ar} \approx 0.192$ as observed in \#19. Argon with the ${ }^{38} \mathrm{Ar} /{ }^{36} \mathrm{Ar}$ ratio slightly higher than those of both SW and Q would be fractionated SW-Ar as in case of $\mathrm{He}$ and $\mathrm{Ne}$ in the snow-AMMs, although trapped 


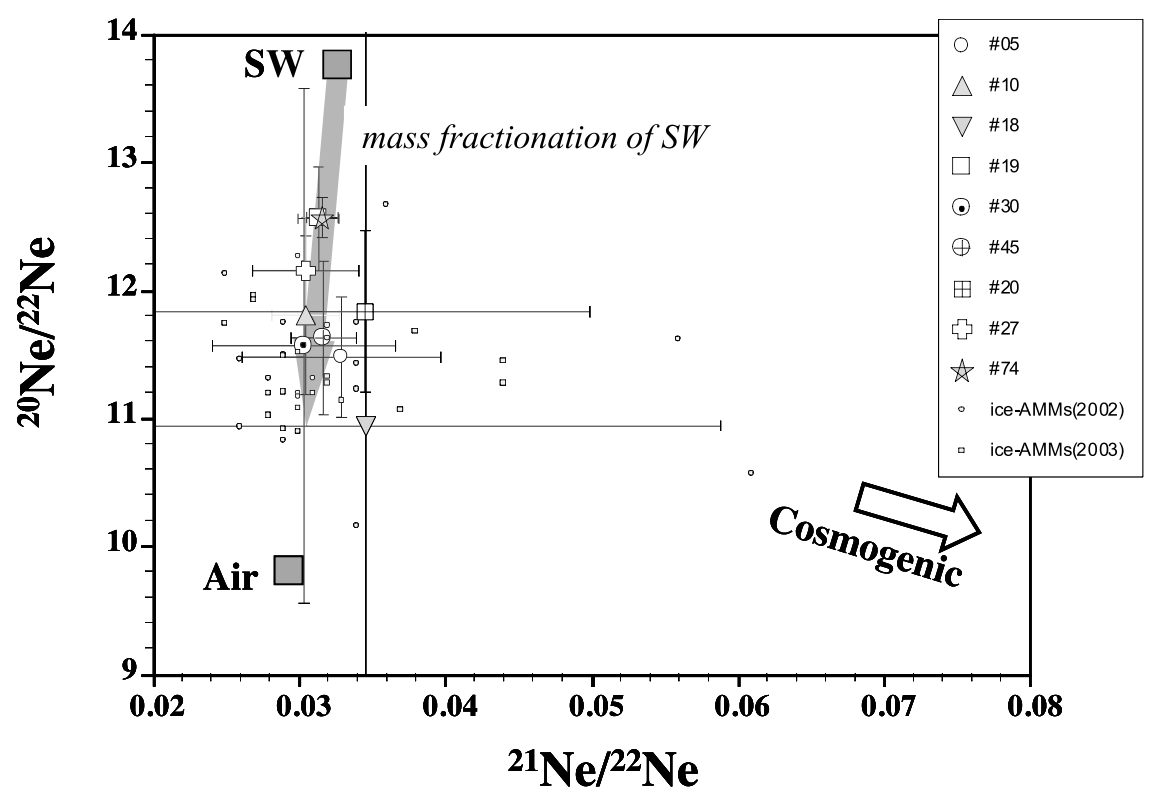

Fig. 7. ${ }^{20} \mathrm{Ne} /{ }^{22} \mathrm{Ne}$ versus ${ }^{21} \mathrm{Ne} /{ }^{22} \mathrm{Ne}$ for total integrated Ne data. The shaded arrow represents mass fractionation line from SW-Ne (e.g. Grimberg $e t$ al., 2008). The fractionation line is close to a mixing line between SW and air. The isotopic ratios for cosmogenic Ne are ${ }^{20} \mathrm{Ne} /{ }^{22} \mathrm{Ne} \approx 0.85$ and ${ }^{21} \mathrm{Ne} /{ }^{22} \mathrm{Ne} \approx 0.90$ (Eugster et al., 1993). Errors are $1 \sigma$.

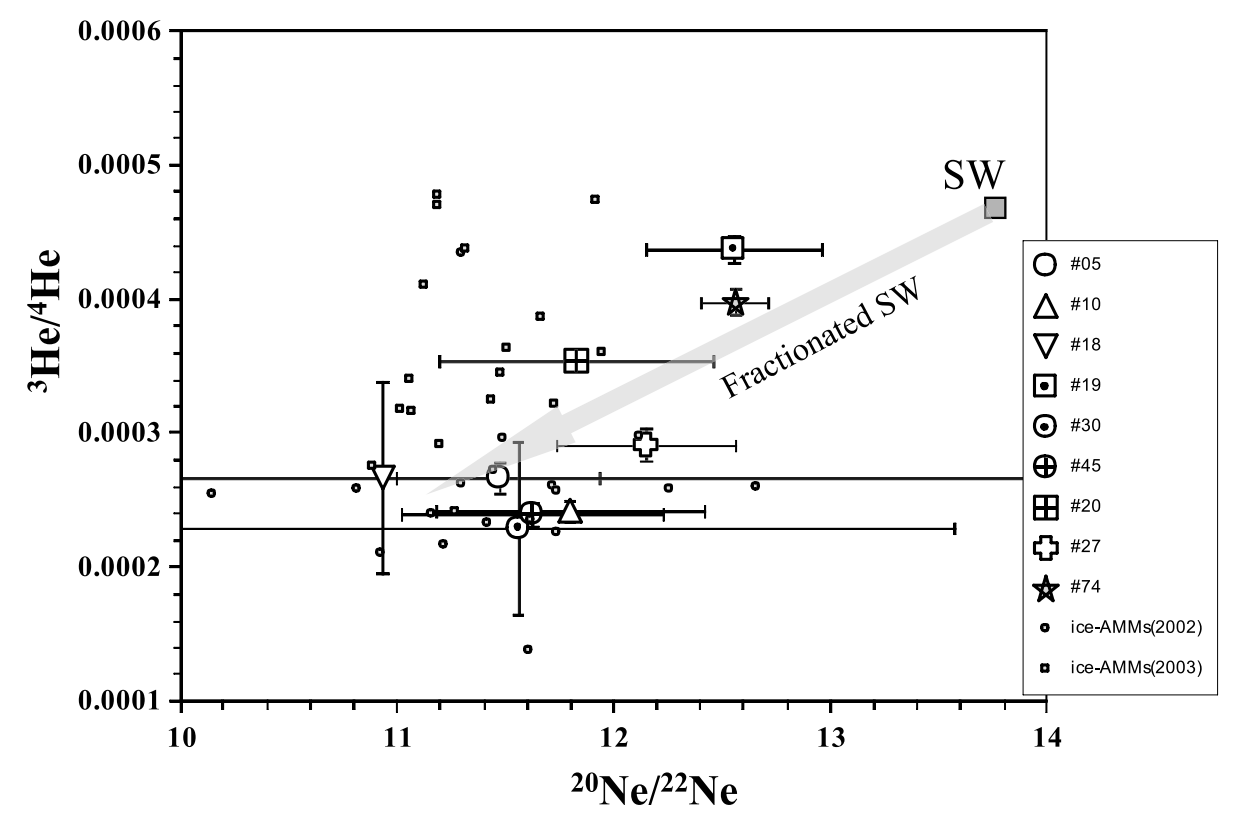

Fig. $8 .{ }^{3} \mathrm{He} /{ }^{4} \mathrm{He}$ versus ${ }^{20} \mathrm{Ne} /{ }^{22} \mathrm{Ne}$ for nine snow-AMMs. Data for ice-AMMs (Osawa and Nagao, 2002; Osawa et al., 2003a) are presented for comparison. Isotopic ratios for $\mathrm{SW}$ are ${ }^{3} \mathrm{He} /{ }^{4} \mathrm{He}=0.000464$ and ${ }^{20} \mathrm{Ne} /{ }^{22} \mathrm{Ne}=13.78$ (Heber et al., 2009). Errors are $1 \sigma$.

Q-Ar might contribute additionally to the fractionated SWAr. Fractionated Q-Ar and contribution of cosmogenic Ar are unlikely because Q-Ar is trapped in Q-phase, retentive to heating, and concentration of cosmogenic Ar would be low as indicated by the $\mathrm{Ne}$ isotopic ratios.

The presence of chondritic heavy noble gases in the samples is clearly seen in Fig. 10, where elemental abundance ratios of $\mathrm{Ar}, \mathrm{Kr}$, and $\mathrm{Xe}$ are presented. Seven samples among nine are shown along a mixing line between noble gases trapped in primitive chondrites and those of solar composition, suggesting that the particles originally contained primordial heavy noble gases and were then irradiated by solar gases. Samples \#20 and \#30 fall along the mixing line between chondritic and atmospheric gases. In contrast to the very high concentrations of solar He in the \#20 particle (Fig. 6), a negligible contribution of solar Ar is indicated. Concentrations of ${ }^{36} \mathrm{Ar},{ }^{84} \mathrm{Kr}$, and ${ }^{132} \mathrm{Xe}$ (Table 2) in this particle are very low. For that reason, any atmospheric noble gas contamination could easily mask the noble gas composition originally trapped in the sample. Likewise, the ability to detect atmospheric contamination in the \#30 particle might be attributable to low concentrations of solar gases, as indicated by the low He in Fig. 5.

Sample \#18 has ${ }^{129} \mathrm{Xe} /{ }^{132} \mathrm{Xe}$ ratio of $1.22 \pm 0.07$ (Table 4), higher than 1.042 for Q-Xe (Busemann et al., 2000). This is a very rare observation with only one 


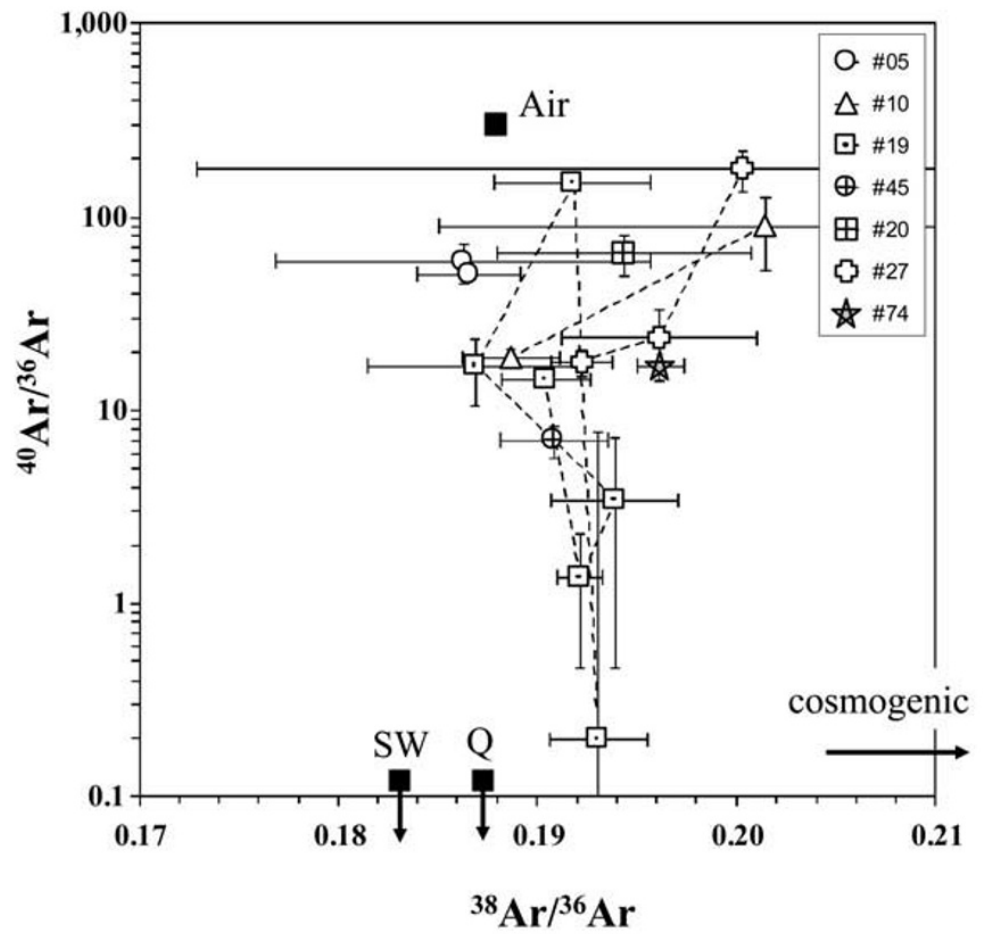

Fig. 9. ${ }^{40} \mathrm{Ar} /{ }^{36} \mathrm{Ar}$ versus ${ }^{38} \mathrm{Ar} /{ }^{36} \mathrm{Ar}$ for seven snow-AMMs. SW ( ${ }^{38} \mathrm{Ar} /{ }^{36} \mathrm{Ar}=0.183$; Heber et al., 2009), Q (0.187; Busemann et al., 2000), Earth's atmosphere $\left({ }^{38} \mathrm{Ar} /{ }^{36} \mathrm{Ar}=0.188\right.$ and ${ }^{40} \mathrm{Ar} /{ }^{36} \mathrm{Ar}=296$; Nier, 1950) and cosmogenic $\mathrm{Ar}\left({ }^{38} \mathrm{Ar} /{ }^{36} \mathrm{Ar} \approx 1.55\right.$; e.g. Eugster et al., 1993) are shown. Errors are $1 \sigma$.

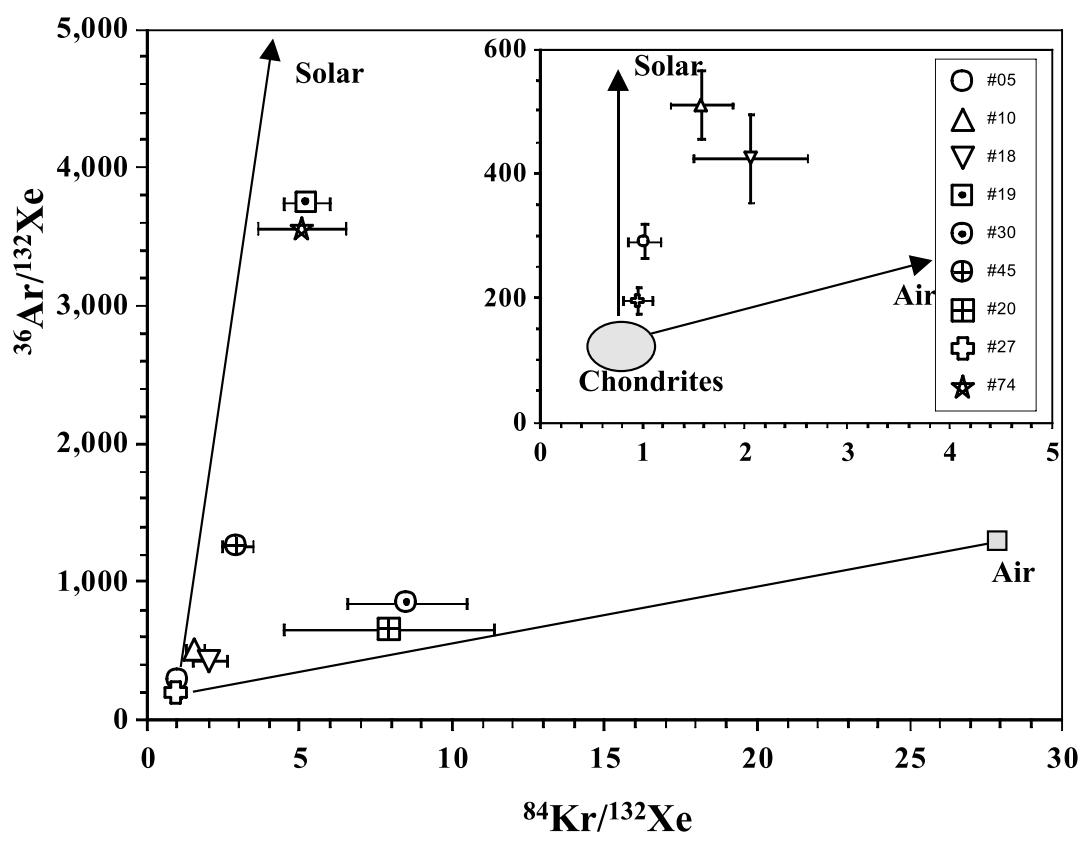

Fig. 10. ${ }^{36} \mathrm{Ar} /{ }^{132} \mathrm{Xe}$ versus ${ }^{84} \mathrm{Kr} /{ }^{132} \mathrm{Xe}$. Data for solar, air, and chondrites are from Ozima and Podosek (2002). Errors (1 $\left.\sigma\right)$ include experimental uncertainties related to noble gas abundances and blank level corrections.

ice-AMM (F96DK038) having a high ${ }^{129} \mathrm{Xe} /{ }^{132} \mathrm{Xe}$ ratio of $1.67 \pm 0.39$ among the 35 samples reported by Osawa and Nagao (2002). They suggested a CK or CV carbonaceous chondrite-like object as a possible source for F96DK038 because CK and CV chondrites often show higher ${ }^{129} \mathrm{Xe} /{ }^{132} \mathrm{Xe}$ than Q-Xe. Particle \#18 also might be derived from these objects, whereas ratios for other samples are indistinguishable from Q-Xe within error limits.

\subsection{He-release temperature and entry velocity of snow-} AMMs

Peak heating temperatures upon atmospheric entry of individual IDPs were estimated as $50 \%$ release temperatures based on the cumulative release of ${ }^{4} \mathrm{He}$ from each IDP by stepwise heating (e.g. Love and Brownlee, 1991, 1994; Nier and Schlutter, 1992, 1993; Joswiak et al., 2007). Graphical expression showing relationship among entry velocities, 


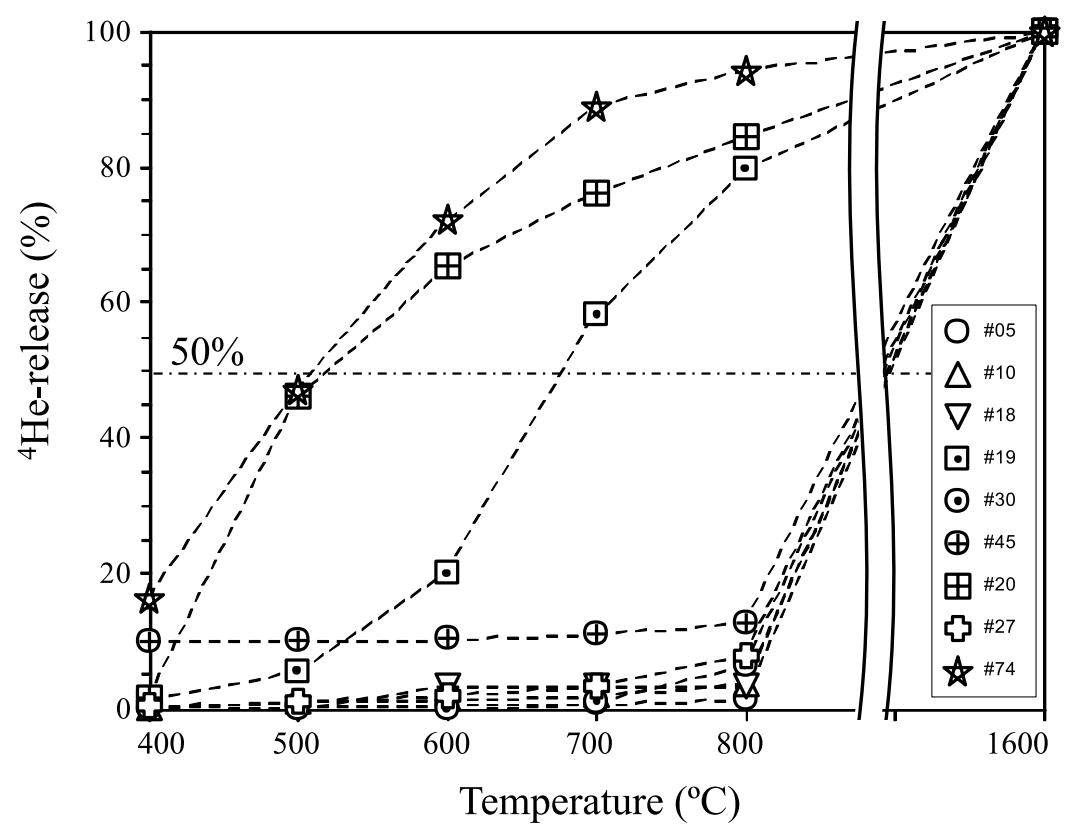

Fig. 11. Cumulative ${ }^{4} \mathrm{He}$ release versus temperatures of the stepwise heating analyses for snow-AMMs.

Table 5. Temperatures for $50 \%$ release of ${ }^{4} \mathrm{He}$ and estimated velocities.

\begin{tabular}{cccccccr}
\hline Sample No. & $\begin{array}{c}\text { Diameter } \\
d^{\prime}(\mu \mathrm{m})\end{array}$ & $\begin{array}{c}\text { Weight } \\
\mu \mathrm{g}\end{array}$ & $\begin{array}{c}\text { Density } \\
\rho^{\prime}\left(\mathrm{g} / \mathrm{cm}^{3}\right)\end{array}$ & $\begin{array}{c}\text { Diameter } \\
d(\mu \mathrm{m})\end{array}$ & $\begin{array}{c}\text { Temperature } \\
{ }^{\circ} \mathrm{C}\end{array}$ & $\begin{array}{c}\text { Entry velocity } \\
\mathrm{km} / \mathrm{s}\end{array}$ \\
\hline D03IB05 & 105 & 0.83 & 1.35 & 71 & $>800$ & & $3)$ \\
D03IB10 & 97 & 0.33 & 0.69 & 34 & $>800$ & & $3)$ \\
D03IB18 & 92 & 0.26 & 0.64 & 29 & $>800$ & & $3)$ \\
D03IB19 & 106 & 0.14 & 0.22 & 12 & 680 & 12 & $3)$ \\
D03IB45 & 120 & 0.48 & 0.53 & 32 & $>800$ & & 310 \\
D05IB20 & 76 & 0.42 & 1.83 & 69 & 500 & & $3)$ \\
D05IB27 & 245 & 18.49 & 2.40 & 294 & $>800$ & & $<10$ \\
D05IB74 & 124 & 1.03 & 1.03 & 64 & 500 & 29 & \\
\hline
\end{tabular}

1) Calculated diameter equivalent to a spherical particle with density $2.0 \mathrm{~g} / \mathrm{cm}^{3}$.

2) Temperature for $50 \%$ release of ${ }^{4} \mathrm{He}$ shown in Fig. 11.

3) Out of the simulated range in Love and Brownlee (1994).

peak temperatures, diameters of particles is given in Love and Brownlee (1994). Plots of cumulative release of ${ }^{4} \mathrm{He}$ for nine snow-AMMs are presented in Fig. 11. Temperatures at $50 \%$ release were $680^{\circ} \mathrm{C}$ for $\# 19$ and $500^{\circ} \mathrm{C}$ for both $\# 20$ and \#74. However the $50 \%$ release temperature could not be determined for other samples because, at most, only $10 \%$ of total ${ }^{4} \mathrm{He}$ was released at temperatures up to $800^{\circ} \mathrm{C}$. Consequently, the $50 \%$ release must occur at some temperatures between the $800^{\circ} \mathrm{C}$ and final $1600^{\circ} \mathrm{C}$ heating steps.

Numerical data including the peak heating temperatures used for the estimation of entry velocities for our samples using the graphical expression (Love and Brownlee, 1994) are presented in Table 5. Densities $\rho^{\prime}$ were calculated using the mean diameters $d^{\prime}$ defined as (major axis + minor axis)/2 (Table 1) and weights assuming a spherical shape for the samples. The densities calculated for samples \#05, \#10, \#18, \#19, \#45, and \#74 ranged from 0.2-1.4 $\mathrm{g} / \mathrm{cm}^{3}$, indicating a porous inner structure. In contrast, the higher densities of 1.8 and $2.4 \mathrm{~g} / \mathrm{cm}^{3}$ calculated respectively for \#20 and \#27 suggest that they have compact interiors or contain coarse-grained minerals. Calculated diameters $d$ equivalent to spherical particles with density $2.0 \mathrm{~g} / \mathrm{cm}^{3}$ are $12-71 \mu \mathrm{m}$, except for the large and dense particle \#27
$(294 \mu \mathrm{m})$.

Entry velocity for the smallest sample \#19 $(d=12 \mu \mathrm{m})$, with a $50 \%$ release temperature of $680^{\circ} \mathrm{C}$, is about $12 \mathrm{~km} / \mathrm{s}$. For samples \#20 and \#74 with diameters of ca. $70 \mu \mathrm{m}$, a $50 \%$ release temperature of about $500^{\circ} \mathrm{C}$ is indicated in Fig. 11. Although a point satisfying both the diameter and the temperature is beyond the simulated area, slow entry velocity $(<10 \mathrm{~km} / \mathrm{s})$ is implied. The entry speeds for these snow-AMMs are distinctly lower than those for cometary dust particles $(>18 \mathrm{~km} / \mathrm{s})$, but in the range for particles of asteroidal origin $(<14 \mathrm{~km} / \mathrm{s})$ (Joswiak et al., 2007). For other samples with the $50 \%$ release temperatures higher than $800^{\circ} \mathrm{C}$, the entry velocities are not constrained.

\subsection{Asteroidal origin for the snow-AMMs?}

The entry speeds less than $14 \mathrm{~km} / \mathrm{s}$ estimated for the studied snow-AMMs might suggest that most snow-AMMs larger than ca. $50 \mu \mathrm{m}$ are of asteroidal origin. Thomas et al. (1995) reported that a cluster IDP L2008*5 (estimated original size, 40-50 $\mu \mathrm{m}$ diameter) had anhydrous mineralogy and experienced $<14 \mathrm{~km} / \mathrm{s}$ entry velocity based on the release temperature of ${ }^{4} \mathrm{He}$. They concluded that the cluster IDP consisted of a chemically and mineralogically diverse mixture was an asteroidal breccia. Because MMs 
\#10 and \#20 seem to have similar mineralogy and morphology to cluster IDP L2008*5, they might also be of asteroidal origin. Although these MMs as well as cluster IDP L2008*5 might have come from asteroids, they were probably derived from asteroids that have not been sampled yet as chondritic meteorites. The \#74 particle is saponite-rich, therefore it appears likely that it was derived from an asteroid that experienced aqueous activity.

No MM similar to samples \#10,\#19, \#20, and \#74, comparable with the high ${ }^{4} \mathrm{He}$ IDPs (Fig. 6), has been recovered yet in ice-AMMs. Additionally, the low densities of 0.22 $1.03 \mathrm{~g} / \mathrm{cm}^{3}$ for $\# 10$, \#19, and \#74 suggest a porous inner structure, which might be fragile and easily destroyed during storage in ice. If these porous particles, whose sizes are larger than those of IDPs, are falling to the Earth, their residence time in the stratosphere would be much shorter than the typical IDPs ( $<10 \mu$ m diameter), resulting in lower probability of stratospheric collection. Thus snow-AMMs may provide an opportunity to study asteroidal MMs of new types, that might be difficult to be collected in both the stratosphere and polar ice.

Another explanation for the porous MM particles in our snow-AMMs is possible. If a large cometary fragile grain enters the atmosphere at high speed ( $\geq 20 \mathrm{~km} / \mathrm{s}$ ), it could be broken into smaller particles that might be effectively decelerated, resulting in multiple particles slowed to $\leq 10$ $\mathrm{km} / \mathrm{s}$. In this case, a low temperature deduced from the $50 \%$ ${ }^{4} \mathrm{He}$ release exhibited by the particle might not be an initial entry heating temperature, but a temperature experienced after slowed down through breakup of the initially entered cometary grain.

\section{Summary}

The laboratory manufactured furnace was examined by measuring snow-AMMs, and showed that it can heat small samples weighing less than $100 \mu \mathrm{g}$ up to ca. $1800^{\circ} \mathrm{C}$ under low blank conditions. The high performance of the furnace revealed in this work demonstrates that it can be applicable to measurement of Itokawa asteroidal regolith materials returned by the Hayabusa mission.

Before the noble gas analyses of snow-AMMs, mineralogical characterizations of the samples were conducted using SR-XRD and SEM-EDX without carbon coating. Noble gases were extracted from each sample by heating in $100^{\circ} \mathrm{C}$ steps from $400^{\circ} \mathrm{C}$ to $800^{\circ} \mathrm{C}$, then melting at $1600^{\circ} \mathrm{C}$. Isotopic compositions and concentrations of noble gases were obtained for nine AMM samples. Released amounts of $\mathrm{He}$ and $\mathrm{Ne}$ varied among the samples, but solar gases predominate. Unlike ice-AMMs, high concentrations of solar ${ }^{4} \mathrm{He}$ on the order of $10^{-2} \mathrm{~cm}^{3} \mathrm{STP} / \mathrm{g}$, comparable with those of high- ${ }^{4} \mathrm{He}$ IDPs, were exhibited for several samples. In contrast to light noble gases $\mathrm{He}$ and $\mathrm{Ne}$, heavy noble gases $\mathrm{Ar}, \mathrm{Kr}$, and $\mathrm{Xe}$ are primordial ones resembling Q-gas that are enriched in chondrites, although additional Ar of fractionated SW is observed in some samples.

Based on the ${ }^{4} \mathrm{He}$ release profiles obtained by stepwise heating, peak heating temperatures during atmospheric entry were estimated for samples following the method by Nier and Schlutter (1993). The temperatures are ca. $500^{\circ} \mathrm{C}$ for \#20 and \#74, ca. $680^{\circ} \mathrm{C}$ for \#19, and $>800^{\circ} \mathrm{C}$ for others.
With the heating temperatures for \#19, \#20, and \#74, initial entry velocities were estimated using a theoretical model for particles entering the atmosphere with various sizes, speeds, and peak heating temperatures (Love and Brownlee, 1994). The speeds obtained for three samples were less than 14 $\mathrm{km} / \mathrm{s}$, suggesting that they were not of cometary origin, but were instead derived from asteroids.

Acknowledgments. We thank S. Nishida and M. Osonoi for their cooperative work of snow-AMMs collection. Surface snow was sampled by Japan Antarctic Research Expedition (JARE) teams in 2004 and 2006. We appreciate H. Motoyama and N. Imae for their transportation of snow in a frozen state from Antarctica to Ibaraki University. This study was supported by a Grant-in-Aid for Scientific Research (B) 17340157 to T. Noguchi. The manuscript was greatly improved by two reviewers, R. Palma and D. Garrison, for their careful reading.

\section{References}

Anders, E. and N. Grevesse, Abundances of the elements: Meteoritic and solar, Geochim. Cosmochim. Acta, 53, 197-214, 1989.

Brearley, A. J. and R. H. Jones, Chondritic meteorites, Planet. Mater., Rev Mineral. Geochem., 36(3), 1-398, 1998.

Brownlee, D. E., Cosmic dust: Collection and research, Ann. Rev. Earth Planet. Sci., 13, 147-173, 1985.

Busemann, H., H. Baur, and R. Wieler, Primordial noble gases in "phaseQ" in carbonaceous and ordinary chondrites studied by closed-system stepped etching, Meteorit. Planet. Sci., 35, 949-973, 2000.

Cresswell, R. G. and R. K. Herd, Canadian Arctic Meteorite Project (CAMP): 1990, Meteoritics, 27, 81-85, 1992.

Duprat, J., C. Engrand, M. Maurette, G. Kurat, M. Gounelle, and C. Hammer, Micrometeorites from Central Antarctic snow: The CONCORDIA collection, Adv. Space Res., 39, 605-611, 2007.

Duprat, J., E. Dobrică, C. Engrand, J. Aléon, Y. Marrocchi, S. Mostefaoui, A. Meibom, H. Leroux, J.-N. Rouzaud, M. Gounelle, and F. Robert, Extreme deuterium excesses in ultracarbonaceous micrometeorites from central Antarctic snow, Science, 328, 742-745, 2010.

Eugster, O., Th. Michel, S. Niedermann, D. Wang, and W. Yi, The record of cosmogenic, radiogenic, fissiogenic, and trapped noble gases in recently recovered Chinese and other chondrites, Geochim. Cosmochim. Acta, 57, 1115-1142, 1993.

Grimberg, A., H. Baur, F. Bühler, P. Bochsler, and R. Wieler, Solar wind helium, neon, and argon isotopic and elemental composition: Data from the metallic glass flown on NASA's Genesis mission, Geochim. Cosmochim. Acta, 72, 626-645, 2008.

Heber, V. S., R. Wieler, H. Baur, C. Olinger, T. A. Friedmann, and D. S. Burnett, Noble gas composition of the solar wind as collected by the Genesis mission, Geochim. Cosmochim. Acta, 73, 7414-7432, 2009.

Hohenberg, C. M., High sensitivity pulse-counting mass spectrometer system for noble gas analysis, Rev. Sci. Instrum., 51, 1075-1082, 1980.

Hudson, B., G. J. Flynn, P. Fraundorf, C. M. Hohenberg, and J. Shirck, Noble gases in stratospheric dust particles: confirmation of extraterrestrial origin, Science, 211, 383-386, 1981.

Iwata, N. and N. Imae, The collection of Antarctic micrometeorites by JARE-41 in 2000 (abstract), Meteorit. Planet. Sci., 36 (Suppl.), A89, 2001.

Joswiak, D. J., D. E. Brownlee, R. O. Pepin, and D. J. Schlutter, Densities and mineralogy of cometary and asteroidal interplanetary dust particles collected in the stratosphere, in Workshop on Dust in Planetary Systems (ESA SP-643), edited by Krueger, H. and A. Graps, 141-144, 2007.

Kehm, K., G. J. Flynn, S. R. Sutton, and C. M. Hohenberg, Combined noble gas and trace element measurements in single IDPs from the L2036 collector, Lunar Planet. Sci. Abst. No 1970, 1998.

Kehm, K., G. J. Flynn, S. R. Sutton, and C. M. Hohenberg, Combined noble gas and trace elements on individual stratospheric interplanetary dust particles, Meteorit. Planet. Sci., 37, 1323-1335, 2002.

Koeberl, C. and E. H. Hagen, Extraterrestrial spherules in glacial sediment from the Transantarctic Mountains, Antarctica: Structure, mineralogy, and chemical composition, Geochim. Cosmochim. Acta, 53, 937-944, 1989

Love, S. G. and D. E. Brownlee, Heating and thermal transform of micrometeoroids entering the Earth's atmosphere, Icarus, 89, 26-43, 1991. 
Love, S. G. and D. E. Brownlee, Peak atmospheric entry temperatures of micrometeorites, Meteoritics, 29, 69-70, 1994.

Mabry, J. C., A. P. Meshik, C. M. Hohenberg, Y. Marrocchi, O. V. Pravdivtseva, R. C. Wiens, C. Olinger, D. B. Reisenfeld, J. Allton, R. Bastien, K. McNamara, E. Stansbery, and D. S. Burnett, Refinement and implications of noble gas measurements from Genesis, Lunar Planet. Sci. Conf. XXXVIII, Abst. \#2412, 2007.

Mahaffey, P. R., T. N. Donahue, S. K. Atreya, T. C. Owen, and H. B. Niemann, Galileo probe measurements of $\mathrm{D} / \mathrm{H}$ and ${ }^{3} \mathrm{He} /{ }^{4} \mathrm{He}$ in Jupter's atmosphere, Space Sci. Rev., 84, 251-263, 1998.

Maurette, M., C. Hammer, D. E. Brownlee, N. Reeh, and H. H. Thomsen, Placers of cosmic dust in the blue ice lakes of Greenland, Science, 233, 869-872, 1986.

Maurette, M., C. Jehanno, E. Robin, and C. Hammer, Characteristics and mass distribution of extraterrestrial dust from Greenland ice cap, Nature, 328, 699-702, 1987.

Maurette, M., C. Olinger, M. C. Michel-Levy, G. Kurat, M. Pourchet, F. Brandstätter, and M. Bourot-Denise, A collection of diverse micrometeorites recovered from 100 tonnes of Antarctic blue ice, Nature, 351, 44-47, 1991.

Nagao, K., Isotope studies on interplanetary dust particles (IDPs)Noble gases_, Chikyukagaku (Geochemistry), 32, 193-201, 1998 (in Japanese with English abstract).

Nagao, K., M. Kusakabe, Y. Yoshida, and G. Tanyileke, Noble gases in Lakes Nyos and Monoun, Cameroon, Geochem. J., 44, 519-543, 2010.

Nakamura, T., N. Imae, I. Nakai, T. Noguchi, H. Yano, K. Terada, T. Murakami, T. Fukuoka, K. Nogami, H. Ohashi, W. Nozaki, M. Hashimoto, N. Kondo, H. Matsuzaki, O. Ichikawa, and R. Ohmori, Antarctic micrometeorites collected at the Dome Fuji Station, Antarct. Meteorite Res., 12, 183-199, 1999.

Nakamura, T., A. Tsuchiyama, T. Akaki, K. Uesugi, T. Nakano, A. Takeuchi, Y. Suzuki, and T. Noguchi, Bulk mineralogy and threedimensional structures of individual Stardust particles deduced from synchrotron X-ray diffraction and microtomography analysis, Meteorit. Planet. Sci., 43, 247-259, 2008.

Nier, A. O., A redetermination of the relative abundances of the isotopes of carbon, nitrogen, oxygen, argon and potassium, Phys. Rev., 77, 789793, 1950.

Nier, A. O. and D. J. Schlutter, Helium and neon isotopes in stratospheric particles, Meteoritics, 25, 263-267, 1990.

Nier, A. O. and D. J. Schlutter, Extraction of helium from individual interplanetary dust particles by step-heating, Meteoritics, 27, 166-173, 1992.

Nier, A. O. and D. J. Schlutter, The thermal history of interplanetary dust particles collected in the Earth's stratosphere, Meteoritics, 28, 675-681, 1993.

Nier, A. O., D. J. Schlutter, and D. E. Brownlee, Helium and neon isotopes in deep Pacific Ocean sediments, Geochim. Cosmochim. Acta, 54, 173182, 1990.

Noguchi, T., T. Nakamura, and W. Nozaki, Mineralogy of phyllosilicaterich micrometeorites and comparison with Tagish Lake and Sayama meteorites, Earth Planet. Sci. Lett., 202, 229-246, 2002.

Noguchi, T., M. Osonoi, T. Nakamura, A. Tsuchiyama, and N. Imae,
Micrometeorites discovered from surface snow near the Dome Fuji station, Antarctica (abstract), 30th Symp. Antarct. Meteorites, NIPR, 8788, 2006.

Nozaki, W., T. Nakamura, and T. Noguchi, Bulk mineralogical changes of hydrated micrometeorites during heating in the upper atmosphere at temperatures below $1000{ }^{\circ} \mathrm{C}$, Meteorit. Planet. Sci., 41, 1095-1114, 2006.

Osawa, T. and K. Nagao, Noble gas compositions of Antarctic micrometeorites collected at the Dome Fuji Station in 1996 and 1997, Meteorit. Planet. Sci., 37, 911-936, 2002.

Osawa, T., K. Nagao, T. Nakamura, and N. Takaoka, Noble gas measurement in individual micrometeorites using laser gas-extraction system, Antarct. Meteorite Res., 13, 322-341, 2000.

Osawa, T., T. Nakamura, and K. Nagao, Noble gas isotopes and mineral assemblages of Antarctic micrometeorites collected at meteorite ice field around the Yamato Mountains, Meteorit. Planet. Sci., 38, 16271640, 2003a.

Osawa, T., K. Nagao, T. Noguchi, A. Nakazawa, and J. Mikada, Remnant extraterrestrial noble gases in Antarctic cosmic spherules, Antarct. Meteorite Res., 16, 196-219, 2003b.

Osawa, T., Y. Yamamoto, T. Noguchi, A. Iose, and K. Nagao, Interior textures, chemical compositions, and noble gas signatures of Antarctic cosmic spherules: Possible sources of spherules with long exposure ages, Meteorit. Planet. Sci., 45, 1320-1339, 2010.

Ozima, M. and F. A. Podosek, Noble Gas Geochemistry, 2nd edition, pp. 286, Cambridge Univ. Press, 2002.

Pepin, R. O., R. L. Palma, and D. J. Schlutter, Noble gases in interplanetary dust particles, I: The excess helium-3 problem and estimates of the relative fluxes of solar wind and solar energetic particles in interplanetary space, Meteorit. Planet. Sci., 35, 495-504, 2000.

Rajan, R. S., D. E. Brownlee, D. Tomandl, P. E. Hodge, H. Farrar, and R. A. Britten, Detection of ${ }^{4} \mathrm{He}$ in stratospheric particles gives evidence of extraterrestrial origin, Nature, 267, 133-134, 1977.

Rubin, A. E. and J. N. Grossman, Meteorite and meteoroid: New comprehensive definitions, Meteorit. Planet. Sci., 45, 114-122, 2010.

Sakamoto, K., T. Nakamura, T. Noguchi, and A. Tsuchiyama, A new variant of saponite-rich micrometeorites recovered from recent Antarctic snowfall, Meteorit. Planet. Sci., 45, 220-237, 2010.

Taylor, S., J. H. Lever, and R. P. Harvey, Accretion rate of cosmic spherules measured at the South Pole, Nature, 392, 899-903, 1998.

Thomas, K., G. E. Blanford, S. J. Clemett, G. J. Flynn, L. P. Keller, W. Klock, C. R. Maechling, D. S. McKay, S. Messenger, A. O. Nier, D. J. Schlutter, S. R. Sutton, J. L. Warren, and R. N. Zare, An asteroidal breccia: The anatomy of a cluster IDP, Geochim. Cosmochim. Acta, 59, 2797-2815, 1995.

Yada, T. and H. Kojima, The collection of micrometeorites in the Yamato Meteorite Ice Field of Antarctica in 1998, Antarct. Meteorite Res., 13, 9-18, 2000.

K.-I. Bajo, T. Akaida, N. Ohashi, T. Noguchi, T. Nakamura, Y. Nakamura, H. Sumino, and K. Nagao (e-mail: nagao@eqchem.s.utokyo.ac.jp) 